 \\ UNITED STATES ATOMIC ENERGY COMMISSION \\ STERIC EFFECTS ON THE FORMATION CONSTANT OF METAL CHELATES OF BETA-DIKETONES \\ By \\ G. A. Guter \\ G. S. Hammond
}

August 1955

Ames Laboratory Iowa State College Ames, Iowa

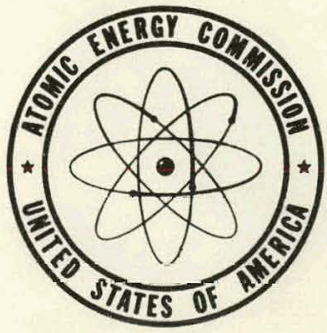

Technical Information Service Extension, Oak Ridge, Tenn. 


\section{DISCLAIMER}

This report was prepared as an account of work sponsored by an agency of the United States Government. Neither the United States Government nor any agency Thereof, nor any of their employees, makes any warranty, express or implied, or assumes any legal liability or responsibility for the accuracy, completeness, or usefulness of any information, apparatus, product, or process disclosed, or represents that its use would not infringe privately owned rights. Reference herein to any specific commercial product, process, or service by trade name, trademark, manufacturer, or otherwise does not necessarily constitute or imply its endorsement, recommendation, or favoring by the United States Government or any agency thereof. The views and opinions of authors expressed herein do not necessarily state or reflect those of the United States Government or any agency thereof. 


\section{DISCLAIMER}

Portions of this document may be illegible in electronic image products. Images are produced from the best available original document. 
Work performed under Contract No. W-7405-Eng-82.

\section{LEGAL NOTICE}

This report was prepared as an account of Governuent spunsured work. Netther the United States, nor the Commission, nor any person acting on behalf of the Commission:

A. Makes any warranty or representation, express or implied, with respect to the accuracy, completeness, or usefulness of the information contained in this report, or that the use of any information, apparatus, method, or process disclosed in this report may not infringe privately owned rights; or

B. Assumes any liabilities with respect to the use of, or for damages resulting from the use of any information, apparatus, method, or process disclosed in this report.

As used in the above, "person acting on behalf of the Commission" includes any employee or contractor of the Commission to the extent that such employee or contractor prepares, handles or distributes, or provides access to, any information pursuant to his employment or contract with the Commission.

This report has been reproduced directly from the best available copy.

Printed in USA. Price $\$ 1.75$. Available from the Office of Technical Services, Department of Cummerce, Washington 25, D. C. 
TABLE OF CONTENTS

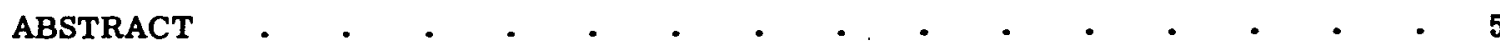

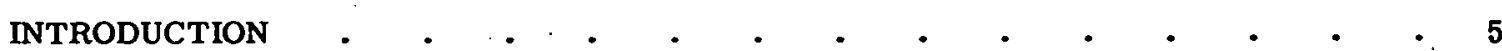

HISTORICAL REVIEW

Influence of Steric Hindrance on Chelation.

Correlations of Formation Constants with Basicities $\quad$ - $\quad$ - $\quad$ • $\quad$ - $\quad$ • $\quad$ - 8

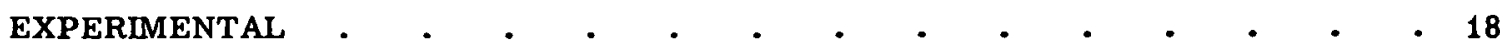

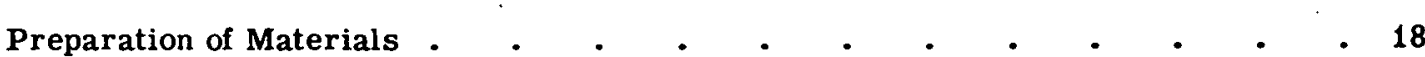

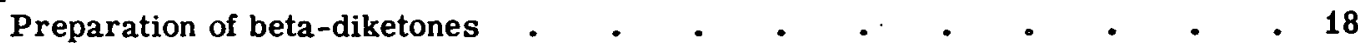

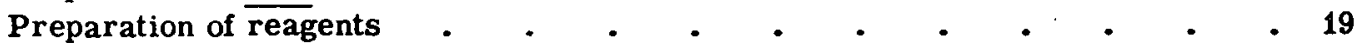

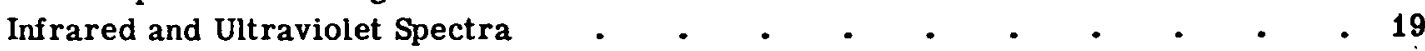

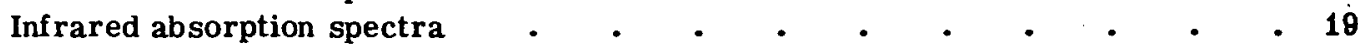

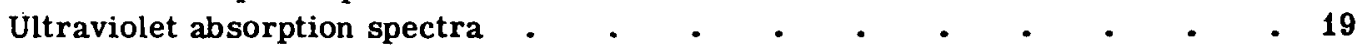

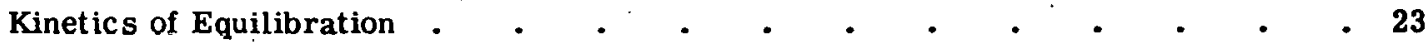

Extractions of Alkali Metal Ions with Dipivaloylmethane . . . • . • . $\quad 25$

Spectrophotometric Measurements of Acid Dissociation Constants - • - • 28

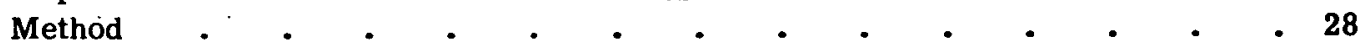

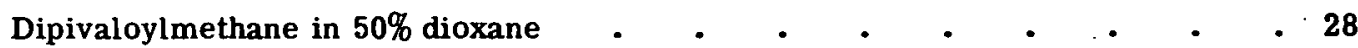

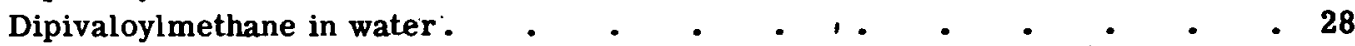

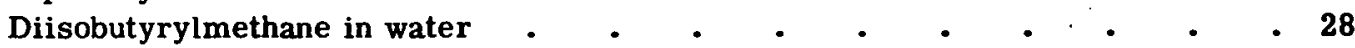

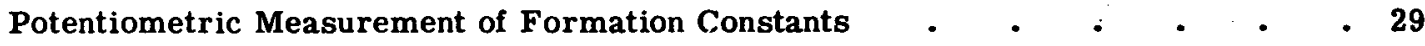

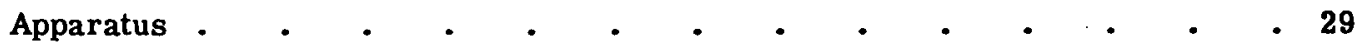

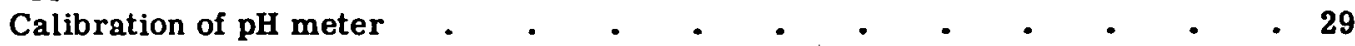

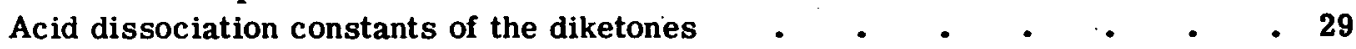

Potentiometric titrations with metal ions and chelating agents . . . . $\quad$ - 29

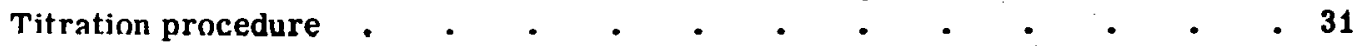

Formation constants of $\mathrm{Zn}(\mathrm{I})$ and Fe(II) chelates $\quad . \quad$ - $\quad . \quad$ - $\quad . \quad$ - 31

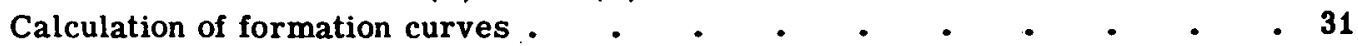

Spectrophotometric Estimation of Formation Constants in 50\% Dioxane . $\quad$ - 31

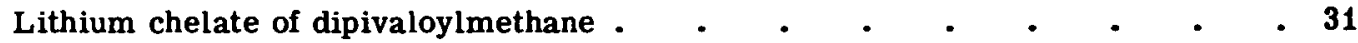

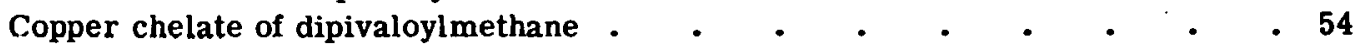

DISCUUSSION

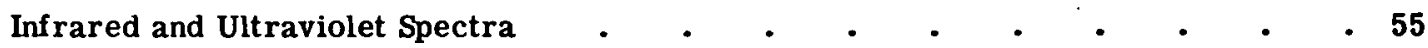

Variation of Acidity with Steric Requirements . $\quad . \quad$. $\quad . \quad$. $\quad . \quad$. $\quad$. 50

Formation Constants of Metal Chelates of beta-Diketones . $\quad$ - $\quad$ - $\quad$ - $\quad$ - $\quad$ - 58

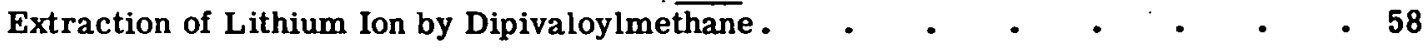

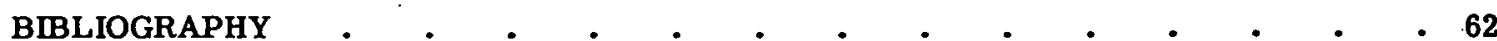


THIS PAGE

WAS INTENTIONALLY

LEFT BLANK 


\title{
STERIC EFFECTS ON THE FORMATION CONSTANT OF METAL CHELATES OF BETA-DIKETONES*
}

\author{
By G. A. Guter and G. S. Hammond
}

\section{ABSTRACT}

Evidence is presented which indicates that chelating ability may be greatly altered by changing the steric requirements of the ligand. A series of formation constants was measured for three beta-diketones. Thermodynamic values could not be obtained but relative concentration constants were. The constants obtained were correlated with each other and with the basicity of the reagent toward a proton. Each correlation indicated that the formation constants for the copper chelates of diisobutyrylmethane and dipivaloylmethane were low and exhibited large separation factors. However, relatively small separation factors were found for metal chelates which do not form square planar complexes.

A simple method for determining the extent of enolization of beta-diketones and the kinetics of enolization is presented. The method makes use of spectrophotometric measurements in the ultraviolet region. Correlations were observed between the $\mathrm{pKa}$ of the chelating agent, the kinetics of enolization, and the kinetics of hydrolysis of corresponding esters. Variations in the $\mathrm{pKa}$ and enol content were explained on the basis of steric effects.

A procedure for the separation of lithium from other alkali metal ions was developed, making use of the selectivity of dipivaloylmethane. The theoretical implications of this selectivity are discussed. Correlation of formation constants with a double basicity scale are reviewed. It is suggested that when using such correlations a chelate effect be taken into account. The application of the Edward and Hammett equation to formation constants is discussed.

\section{INTRODÚCTION}

Since the advent of the theoretical treatment of Bjerrum(1) on the measurement of formation constants and the application of this method to organic chelating agents, very few systematic studies have been carried out in order to correlate steric requirements of ligands with their chelating abilities. It is the primary object of this study to contribute to the meager knowledge concerning steric effects in chelation from the vast field of theoretical organic chemistry where steric effects are quite well understood.

The recent widespread use of chelating agents as analytical reagents, their commercial application, and use as medicinals attest to the importance of increasing the theoretical knowledge of metal chelates. It is in this field that analytical chemistry searches for the specific, selective reagent. Although it was not anticipated at the beginning of this study that a selective reagent would be among the compounds studied, the finding of one gives encouragement to future systematic studies in this field.

* This report is based on a Ph.D. thesis by G. A. Guter submitted August, 1955 to Iowa State College, Ames, Iowa. This work was performed under contract with the Atomic Energy Commission. 
The chelating ability of the three beta-diketones was studied by means of their relative formation constants in 75 percent dioxane. A definite trend was observed as the steric requirements of the chelating agent were increased. The steric effect manifests itself in three ways; (a) the separation factor becomes smaller for tetrahedral complexes; (b) for the square planar complex the formation constant becomes relatively smaller and the separation factor is large; (c) the relative solubilities in water and organic solvents and the difference in the ease of formation of the alkali metal chelates change markedly. A theory concerning the selectivity of dipivaloylmethane is given.

The work reported here should stimulate synthesis of selective reagents and systematic studies of this type.

\section{HISTORICAL REVIEW}

\section{Influence of Steric Hindrance on Chelation}

Few systematic studies have been carried out with the purpose of correlating the storic requirements of ligands with their chelating properties. Among the first isolated instances which demonstrate the steric effect in chelation was a study by Morgan and Thomasson (2) who found that if the 3-position of acetylacetone was substituted with an isopropyl or secondary butyl group, none of the usual colored copper and ferric chelates were formed. If a straight chain alkyl group was the substituent, typical chelates were formed. This observation was the first to show the deviation in the properties of monoalkylated open chain diketones. Similar deviations had been noticed by Leser (3) who observed that 2-acetyl-dimethylcyclohaxanone containing a branchcd chain substituted on the methylene group gave no copper chelate.

The study carried out by Morgan $(2,4,5)$ pointed out that aklyl substituted acetylacetones which were substituted with branched chains at either the terminal carbon or central carbon atom were less capable of forming derivatives from tellurium tetrachloride than the unsubstituted diketone.

The tellurium complexes seemed to have very different properties than the chelates formed by other metals. The difficulty of their formation was not, however, attributed to a steric effect since 3,3-diethylacetylacetone gave an excellent tellurium derivative and failed to give a ferric or copper chelate. Also the diketone anions were found as bivalent radicals in the condensations with selenium and tellurium tetrachlorides. In keeping with these facts the structure of tho oomplex was proposed as<smiles>C=C1O[C@H](Cl)CC(=O)C1(CC)CC</smiles>

Similarly, 3-isopropylacetylacetone gave no reaction with cupric or ferric ions but rcadily gave the tellurium derivative.

The inability of 3-isopropylacetylacetone to chelate and the low formation constant of the 3 -methylacetylacetone copper chelate was explained as a case of interference with the planar cunfiguration of the chelate ring, which is necessary for complete resonance.

It has been well established that any substitution in the 2-position of 8-hydroxyquinoline prevents the precipitation of an aluminum complex. Irving, Butler, and Ring (7) concluded that the effect was due to the steric hindrance provided by the group in the 2-position.

In order to further investigate the blocking effect of the 2-substituted 8-hydroxyquinolines, Freiser et al. $(8,9)$ determined the stabilities of several metal chelates of 2-methyl- and 2phenyl-8-hydroxyquinoline. The metals used were $\mathrm{Cu}$ (II), $\mathrm{Ni}(\mathrm{II}), \mathrm{Co}$ (II), $\mathrm{Zn}$ (II), $\mathrm{Mn}$ (II), $\mathrm{Pb}$ (II), $\mathrm{Cd}(\mathrm{II})$, and $\mathrm{Mg}$ (II). The chelates of both 2-substituted 8-hydroxyquinoline have a less basic nitrogen atom than the corresponding 8-hydroxyquinolinates. Although 2-phenyl-8-hydroxyquinoline has a less basic nitrogen atom than the unsubstituted chelating agent, Freiser attributes the lower stability of the 2-substituted chelates to some type of steric hindrance. This 
is justified since the 2-methyl group increases the basicity of the nitrogen toward protons and decreases the stability of the complex. It was also shown that the stability of the nickel chelates of these hindered agents was considerably less than would be expected, or a larger steric effect was operating in the case of $\mathrm{Ni}(\mathrm{I})$ than the other metals. Freiser explains that this is so because $\mathrm{Ni}$ (II) has a tendency to form planar complexes, and substitution at the 2-position would give rise to either a strained or distorted planar configuration or possibly even that of a tetrahedron.

A comparison of the $\Delta \mathrm{H}^{\circ}$ values obtained for these reaction shows that where 2-substitution is involved the heats of chelation are only half that found associated with the respective chelates for the 4-methyl compound. It is thus reasonable to assume that the presence of the 2-methyl group prevents the close approach of the two ligands around the metal atom regardless of the preferred configuration. Freiser demonstrated that the magnitude of the steric effect increases with decreasing metal size by plotting the thermodynamic functions of the transchelation reaction where the 2-methyl-8-hydroxyquinoline anion is exchanged for the 4-methyl8-hydroxyquinoline ligand. The plot reveals that $T \Delta S^{\circ}$ and $\Delta H^{\circ}$ for the reaction are linear functions of the crystal radii of the metals, $\Delta \mathrm{H}^{\circ}$ for $\mathrm{Ni}(\mathrm{II})$ deviating considerably from linearity.

Another interesting point brought out in Freiser's data is that there is a much greater entropy increase for the formation of a hindered chelate. It was explained that the extra shielding of the 2-methyl group can more efficiently remove water molecules from the aquated metal ion. The decreased solvation would also help contribute to the smaller $\Delta H^{\circ}$ value.

Freiser's explanation that $\mathrm{Ni}(\mathrm{m})$ has a tendency to form planar complexes should not pass without comment. Martell and Calvin (10) point out that all compounds in which nickel is bound to four oxygen atoms, such as bisacetylacetone nickel, are paramagnetic. Mellor and Lockwood (11) have found that such chelates show considerable ionic character accompanied by considerable deviation of bond angles from the planar structure. If nickel is bonded either to nitrogen or to sulfur the diamagentic or square planar structures are preferred.

Since the replacement of hydrogen atoms of ammonia by alkyl groups has a base strengthening effect, it is reasonable to assume that the strength of metal-amine complexes might be strengthened as well. This is the case with the silver-amine complexes which have most extensively studied $(12,13)$. Secondary amines give complexes of lower stability than would be expected from their proton basicity, and this effect is even more marked with tertiary aliphatic amines. The base strengthening effect of alkyl substitution is necessarily accompanied by an increase in molecular volume, and steric interference between amine molecules coordinated to a metal, and between amine molecules and solvated water, will tend to reduce the stability. of such metal complexes.

It was not surprising to Irving and Griffiths (14) when they found that the N-alkylsubstituted ethylenediamines showed decreasing ability to complex with $\mathrm{Cu}$ (II), even though the alkyl substitutents increased the stability of the proton complex with the same ligands. This, of course, they attributed to steric factors. A portion of their data is presented here.

Table I - Stability Constants of Copper (II)

Complexes of $\mathrm{N}$-alkylethylenediamines

$\begin{array}{lrcr}\text { Alkyl substituent } & \log \mathrm{K}_{1} & \log \mathrm{K}_{2} & \mathrm{pK}_{\mathrm{BH}^{+}} \\ \text {H } & & & \\ \text { Methyl } & 10.73 & 9.30 & 10.18 \\ \text { Ethyl } & 10.55 & 8.56 & 10.40 \\ \text { i-Propyl } & 10.10 & 8.38 & 10.56 \\ & 9.07 & 7.45 & 10.62\end{array}$

Although steric effects may be operating in this case, it is difficult to obtain a true evaluation unless the base strengthening effect of the alkyl substituent is first understood. In this case a comparison of formation constants with ligand basicity may not be justified. According to the views of Trotman-Dickenson (15) there is actually a greater difference between the basicities of primary and more highly substituted amines than the measurements obtained in water reveal. He suggests that the greater solvation of ammonium ions than free amines makes the 
ammonium ions appear more stable when their dissociation constants are measured in water than when measured in an inert solvent. This stabilization increases with the number of protons in the amine cation, due to increased hydrogen bonding with the solvent.

Trotman-Dickenson was unable to obtain correlation between the catalytic coefficients of aniline bases for the decomposition of nitramide and their dissociation constants by one simple Bronsted equation. However, each class of amines given below obeyed a separate equation:

$\begin{array}{ll}\text { Tertiary amines } & k_{c}=3.8 \times 10^{-5} \mathrm{Ka}^{.64} \\ \text { Secondary amines } & k_{c}=1.1 \times 10^{-5} \mathrm{Ka}^{\cdot 64} \\ \text { Primary amines } & k_{c}=4.1 \times 10^{-8} \mathrm{Ka}^{.64}\end{array}$

The three types of amines could be correlated by the same Bronsted equation if the dissociation constants measured in $\mathrm{m}$-cresol were used. This led this worker to suggest that solvation effects in water lead to misunderstanding as to the true proton affinity of amines.

Unless these same solvation effects occur with metal amine complexes, the interpretation of free energy correlations with the pKa of the ligand is made only on unsound premises.

'The type of steric effect observed by Irving and Griffiths (loc.cit.) may be classified as both the F and B strain described by Brown (16). The F or "frontal" strain acts between chelated ligand and solvent molecules around the mono-chelated metal. The B strain arises from the placement of three substitutents plus a hydrogen atom on a single nitrogen atom and thus forces three of the normally tetrahedral bonds away from each other.

There are several other examples of steric inhibition to the formation of metal chelates (17). The foregoing have been singled out and they are the most systematic and the most complete studies.

Steric effects observed in chelation may be divided into the following three classes:

1. Steric requirements may influence the size of the chelate ring.

2. They may interfere with coplanarity of a chelate ring where resonance is possible.

3. Steric requirements may be large near the reaction site and thus interfere either directly with the metal bond or with other basic substances surtounding the metal such as solvating molerules.

The presence of a steric effect in any one class does not exclude its presence in another, and it is quite conceivable that 2 and 3 may occur frequently together.

The influence of the size of the chelate ring is quite well understood (18), five and six membered rings being the most stable due to decreased strain. Recently Irving et. al (19) have further discussed this effect in the light of Schwarzenbach's predictions concerning ring size and the chelate effect (20). Similarly the interference with the coplanarity of the ring has been widely discussed (21). At the present time Irving is carrying on investigations of this problem using 3,3'-substituted dipyridyls (22). This type of interference is also demonstrated by 3substituted acetylaceone where the central substituent will interfere with the terminal methyl groups and force the chelate ring out of planarity.

The following discussion.will be centered about the third type of steric effect mentioned above. This type of steric effect does not have its parallel effects in other organic structures as the first two classifications seem to, but rather is more related to effects found in sterically hindered Lewis acid-base reactions.

\section{Correlations of Formation Constants with Basicities}

Before searching for steric effects with the use of formation constants, a relationship between the strength of the chelate compound and more fundamental properties must be sought. It appcars that therc is no such single property to be found.

Calvin and Wilson (6) were the first to recognize the relationship between basic strengths of the ligands and formation constants of chelates. The group of compounds which was correlated contained substituted salicylaldehydes, naphthaldehydes, and beta-diketones. These compounds fell into at least two and probably four classes, each showing a linear relationship between the log formation constant for $\mathrm{Cu}$ (II) chelates and $\mathrm{pKa}$ of the chelating agent. 
The analysis of this relationship indicated that both copper and hydrogen ions are bound partly by the same forces to the ligand and partly by different forces. The greatest difference according to them, and which accounted for the four separate groups, was the extent to which hydrogen and copper participate in the resonance of the chelate ring. This conclusion was drawn from the fact that each group of chelating agents involved chelate rings in which the bond order assigned to the carbon-carbon bonds was unique. In acetylacetone a bond order of 2 may be assigned, in salicylaldehyde 1.67, in 2-hydroxy-1-napth-aldehyde 1.5, in 2-hydroxy-3-naphthaldehyde 1.33. Resonance in the enol ring has been pointed out as one of the major contributing factors to the stabilization of the enol form (23), and Calvin and Wilson argue that the bond order is a measure of the extent to which the chelate may participate in resonance structures such as those shown in Structures I to VIII.<smiles>CC(=O)c1ccccc1O[Na]</smiles>

I<smiles>CC(O[Ga])=C1C=CC=CC1=O</smiles>

II<smiles>CC1=C2C=CC=C[C@@H]2O[Y10]O1</smiles>

III<smiles>CC1O[Al]Oc2ccccc21</smiles>

IV<smiles></smiles><smiles>CC(=O)c1ccccc1O[Al]=O</smiles><smiles></smiles>

VII<smiles></smiles>

VIII

There are intimations in the data of Calvin and Wilson which may help deciding the importance of Structures V and VI. Substitution of a methoxyl group in the four position of salicylaldehyde should provide additional stability to Structures III and IV by the electron releasing property of this substituent.

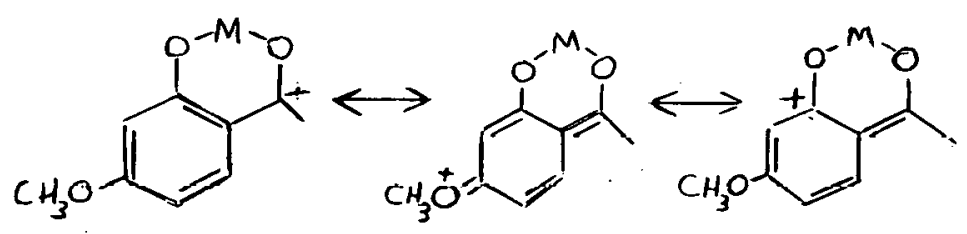


Thus the 4-methoxy group should greatly contribute to the stability of the chelate; actually this effect is observed. The 4-methoxysalicylaldehyde has a greater formation constant than the unsubstituted, or even the 3-methoxy compound, even though the basicity toward a proton is greater for the unsubstituted compound. The formation constants of the copper (II) chelates of these compounds are plotted against the Hammett sigma constants in Figure 1, and the large positive deviation of the 4-methoxy compound is clear.

If the beta-diketones are considered next, a major deviation occurs in 3-methylacetylacetone exhibiting suppressed chelating properties. As is discussed on page 55, the enol form of 3-methylacetylacetone is hindered and does not allow planarity of the ring. The enol is thus thought to exist mainly in the acyclic form. Slight deviation may be accounted for because these two compounds are much less enolic than the others listed here.

A series of sixteen formation constants of beta-diketones has also been obtained for $\mathrm{Cu}$ (II) by Van Uitert (24). Excellent linear relationships have been obtained between these constants and the $\mathrm{pKa}$ of the chelating agent.

From the above correlations it is apparent that the two fundamental properties to which formation constants are related are the $\mathrm{pKa}$ of the reagent and a factor associated with resonance stahilization of the chelate ring.

In the remaining part of this section a model chelating agent is constructed, at least in a qualitative fashion, with the aid of new data taken from the literature as well as some previously given. The properties of more complex chelating agents are then inferred from those of the model, especially where non-conformity is observed, so that later steric effects may be better evaluated.

Recently, complex ion equilibria have been correlated on a double basicity scale by Edwards (25). The correlation of 108 formation constants is made on the basis of the equation

$$
\log \frac{\mathrm{k}}{\mathrm{Ko}}=\underline{\alpha} \mathrm{En}+\underline{\beta} \mathrm{H}
$$

where $\mathrm{k} / \mathrm{Ko}$ is a relative (to water) rate or equilibrium constant and En is a nucleophilic constant characteristic of the ligand. $H$ is the relative basicity of the donor to protons, and $\underline{\alpha}$ and $\underline{\beta}$ are substrate constants, characteristic, in this case, of the metal ion. By definition

$$
\begin{aligned}
& H=p K a+1.74 \\
& E n=E^{\circ}+2.60
\end{aligned}
$$

where $\mathbf{E}^{\circ}$ is the electrode potential given by Latimer for oxidative dimerizations of the type

$$
2 \mathrm{I}^{-}=\mathrm{I}_{2}+2^{\mathrm{e}-}
$$

Although formation constanto of metal chclates arc not correlated by Edwards, thosc cor relations which involve metal ions and monodentate ligands such as ammonia, pyridine, phenoxide ion, or any monodentate group which could be incorporated into a polychelating agent, may possibly serve a useful purpose. This type of correlation appears to be a step forward from the previously discussed cor relation where a double basicity scale was intimated.

It is useful to observe the fundamental relationship between the Hammett rho sigma correlations (26) and those of Edwards. When considering formation constants of the type,

$$
\begin{aligned}
& \text { Ao }+M=\text { MAo } \\
& A+M-M A
\end{aligned}
$$

where Ao and $A$ are anions of benzoic acid and substituted benzoic acids, respectively, the Hammett correlation demands the following relationship:

$$
\log \frac{\mathrm{k}}{\mathrm{k}_{\mathrm{o}}}=\rho \sigma
$$




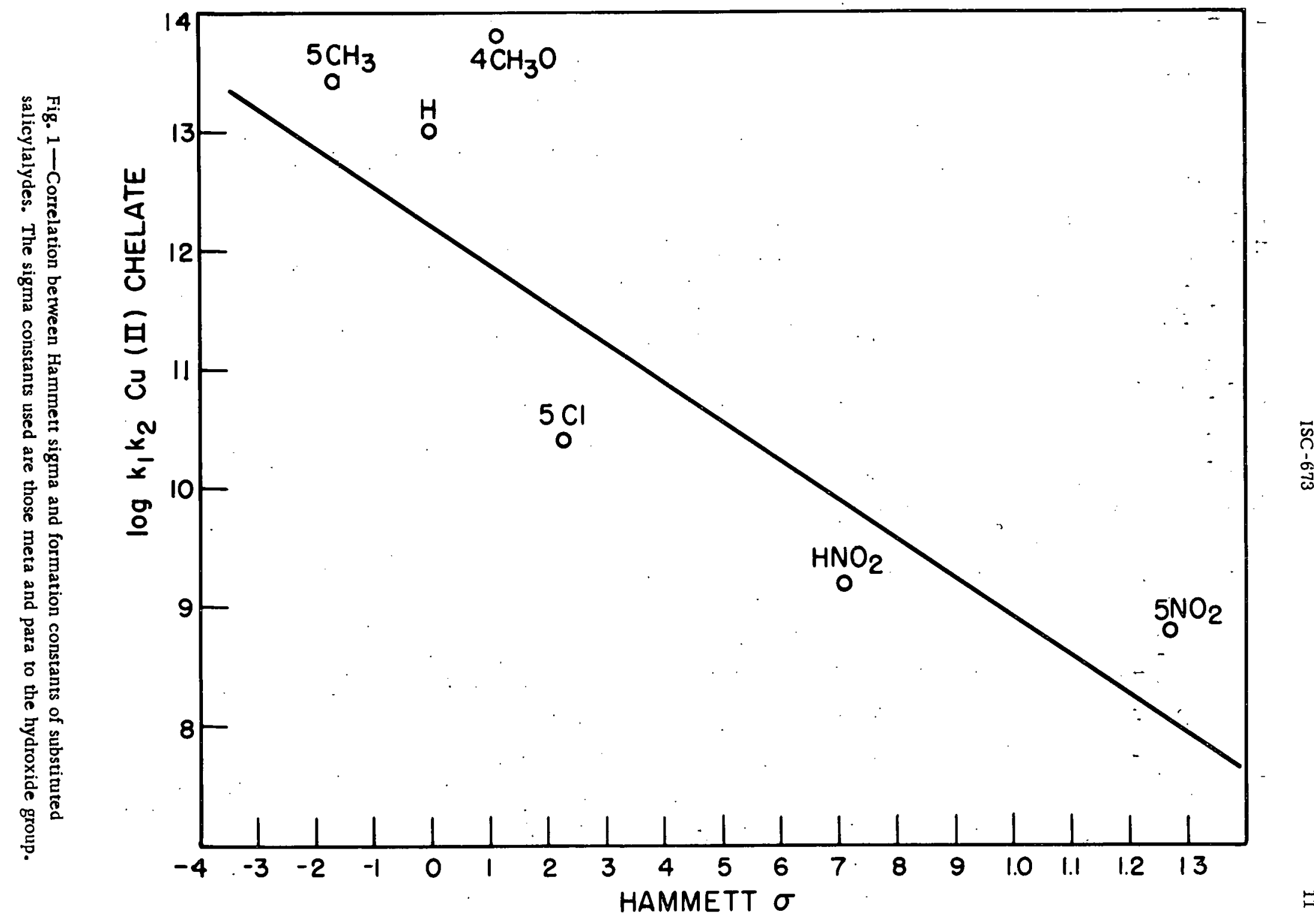


where $\mathrm{k}$ is the equilibrium constant for reaction (1) and $\mathrm{k}_{\mathrm{o}}$ is the equilibrium constant for reaction (2), rho is a reaction constant and sigma is a constant characteristic of the meta or para substituent in $A$.

According to the Edwards correlation the following relationships would hold:

$$
\begin{aligned}
& \log \frac{\mathrm{k}}{\mathrm{K}_{0}}=\underline{\alpha} \mathrm{En}+\underline{\beta}(\mathrm{pKa}+1.74) \\
& \log \frac{\mathrm{k}}{\mathrm{K}_{\mathrm{o}}}=\underline{\alpha} E n_{0}+\underline{\beta}\left(\mathrm{pKa}_{\mathrm{o}}+1.74\right)
\end{aligned}
$$

then

$$
\log \frac{k}{k_{o}}=\underline{\alpha}\left(E n-E n_{o}\right)+\underline{\beta}\left(p K a-p K a_{o}\right)^{*}
$$

Comparing this with the Hammett relationship it is found that

$$
\begin{aligned}
& \mathbf{E n}=\operatorname{En}_{0} \\
& \underline{\beta}=\underline{\rho}
\end{aligned}
$$

This appears to be a necessary condition for conformity to the Hammett equation. It is entirely possible that substituents capable of digtributing the electronic charges uver a wider area are capable of influencing En and produce deviations from the $\rho \underline{\sigma}$ treatment. Furthermore, it is shown by the values of En and $H$ given by Edwards that no dependent relationship exists between them. Thus, any linearity found between formation constants and pKa cannot be a result of the linear dependence of $\left(E n-E n_{0}\right)$ upon pKa. Deviations for complex ion equilibria would be expected to be larger than for carbon displacement reactions, since the $\alpha$ values are much larger for the metal ion substrates.

Data to test the relationship between Hammett. and Fidwards treatmonts have boon prcocntcd by Milburn (27). It was found that equilibrium constants for the reaction

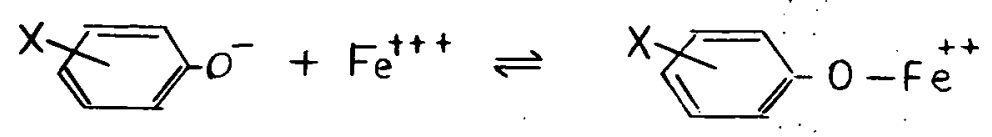

where $\mathrm{X}=\underline{\mathrm{p}}-\mathrm{CH}_{3}, \mathrm{H}, \underline{\mathrm{p}}-\mathrm{Br}, \underline{\mathrm{m}}-\mathrm{Br}$, and $\underline{\mathrm{p}}-\mathrm{NO}_{2}$, showed a scattering of points for the Hammett plot which was greater than expected from the random errors. The deviations of points were about ten times the average standard deviation in log formation constant. Milburn suggests that the scatter could be accounted for by potential energy terms of a type not operative for the acid dissociation; for example, the $\mathrm{O}-\mathrm{Fe}$ bond could have some double bond character.

The data are replotted in Figure 2, and a slope required by the Edwards equation (0.56) is drawn. Any large deviations must be due to large differences in En. It is noted that the $\underline{p}-N_{2}$ compound decreases the complex stability more than that predicted. If double bonding for the O-Fe bond is Important, a $\mathrm{p}-\mathrm{NO}_{2}$ group would decrease the complex stability by its electron withdrawing properties.<smiles></smiles><smiles>[CH]1CC1</smiles><smiles>[O-][N+](O)=C1C=CC(=[O+]F)C=C1</smiles>

* This implies a perfect fit of the Edwards equation. There is the possibility that when the Hammett equation breaks down, the Edwards equation will also break down implying a relationship such as $\log \mathrm{k} / \mathrm{K}_{\mathrm{o}}=\underline{\alpha E n}+\beta \mathrm{H}+\mathrm{f}(\mathrm{g})$, where $\mathrm{q}$ are other molecular parameters. 


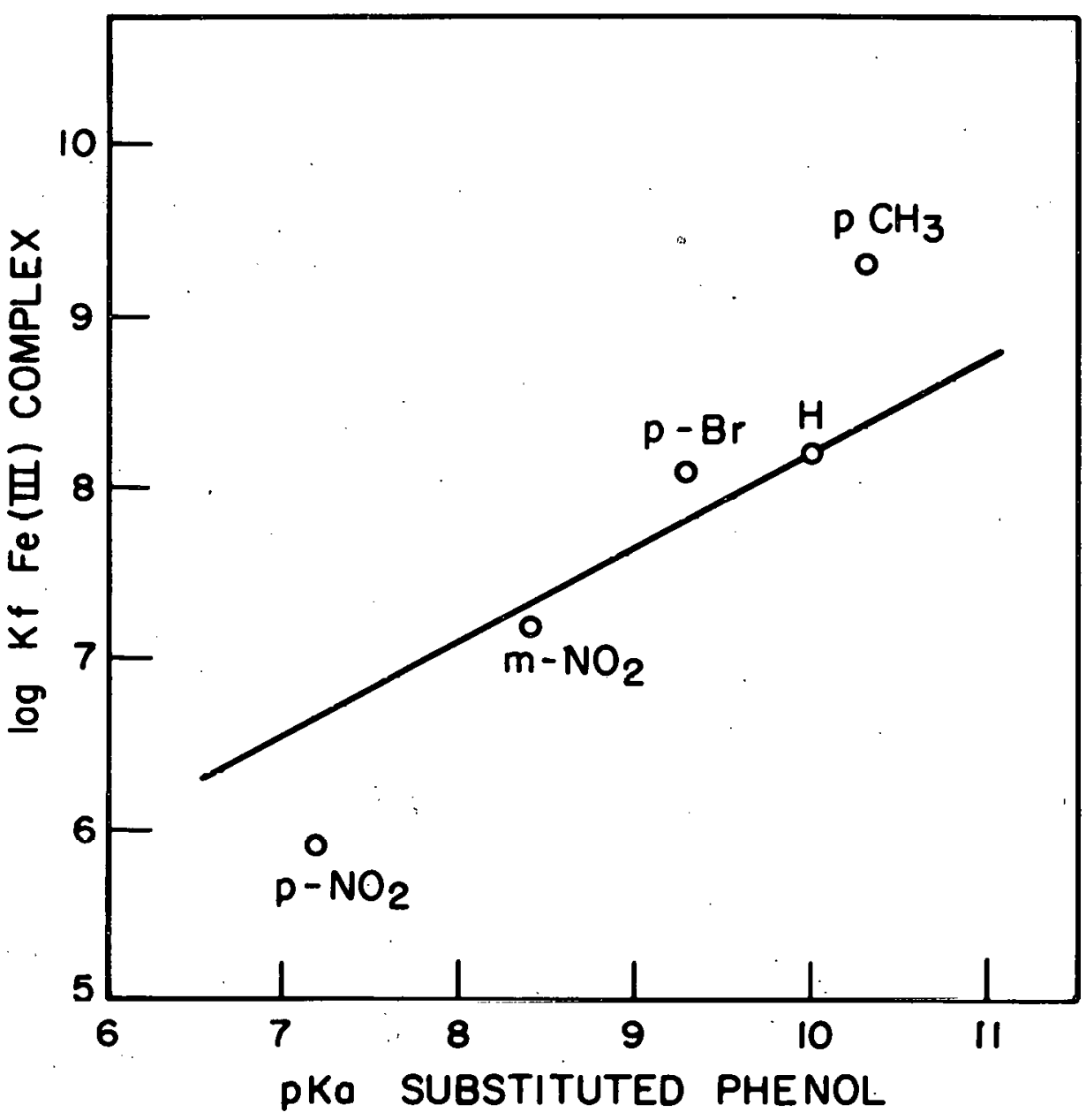

Fig. 2-Correlation predicted by Edwards equation. 
When reactions of the type

$$
\mathrm{Cu}+4 \mathrm{~A}=\mathrm{CuA}_{4}
$$

when correlated by Edwards, it was found that for $\mathrm{Cu}(\mathrm{II})$

$$
\begin{aligned}
& \underline{\alpha}=4.69 \\
& \underline{\beta}=.958 .
\end{aligned}
$$

That the formation constants of $\mathrm{Cu}(\mathrm{II})$ chelates are not correlated by this equation is shown by the predicted slope of $\operatorname{dlog} \mathrm{K}_{(\mathrm{chel})} / \mathrm{dpKa}=0.958$. Calvin and Wilson (loc.cit.) show that this slope is 1.71, nearly twice that predicted by the Edwards equation. This is understood since the chelate effect would enhance the basicity of the ligands if they are in the form of a bidentate ligand.

The above facts suggest the following:

a. Where substitution on the ligand is involved in some eascs it is possible to vary the pKa of the nucleophile without changing the En values.

b. For a group of chelating agents where the pKa varies with substitution the chelate effect remains constant, i.e.

$$
\log \mathrm{k}(\mathrm{chel})=\underline{\mathrm{x}} \log \mathrm{kf}+\underline{\mathrm{x}}
$$

where

$$
\begin{aligned}
& \log k(\mathrm{chel})=\log \frac{\left[\mathrm{M}(\mathrm{Ch})_{2}\right]}{[\mathrm{M}][\mathrm{Ch}]^{2}} \\
& \log \mathrm{k}_{\mathrm{f}}=\log \frac{\left[\mathrm{M} \mathrm{B} \mathrm{B}_{4}\right]}{[\mathrm{M}][\mathrm{B}]^{d}}
\end{aligned}
$$

where $\mathrm{Ch}$ is a chelating agent and $\mathrm{B}$ is a similar monodentate group, and the large and small chi's are constants associated with the chelate effect.

The (b) assumption requires a linear free energy relationship between the reactions

$$
\begin{aligned}
& M+4 B=M_{4} \\
& M+2 C h=M(C h)_{2} .
\end{aligned}
$$

Appropriatc crampleo would bo whoro the B's aro eubstituted pyridines and the Ch's are cor= respondingly substituted bipyridyls formed by joining two B groups together.

Irving, et al., (28) have shown that such a linear relationship exists when the metal.ion is varied from $\mathrm{Co}(\mathrm{II})$ to $\mathrm{Ni}(\mathrm{II})$ to $\mathrm{Cu}(\mathrm{II})$ and the first chelate effect, chel(I), for ethylenediamine is

$$
\operatorname{chel}(I)=\frac{\log \mathrm{K}_{1}(\text { en })}{\mathrm{K}_{1} \mathrm{~K}_{2} \mathrm{NH}_{3}}=0.20 \log \mathrm{K}_{1} \mathrm{~K}_{2} \mathrm{NH}_{3}+1.40
$$

and

$$
\operatorname{chel}(I)=\frac{\log \mathrm{K}_{2}(\mathrm{en})}{\mathrm{K}_{9} \mathrm{~K}_{4}\left(\mathrm{NH}_{3}\right)}=0.32 \log \mathrm{K}_{3} \mathrm{~K}_{4}\left(\mathrm{NH}_{3}\right)+2.43
$$

and found the chel (I) and chel (II) diminished as the number of methylene groups between the terminal groups increased. 
It is apparent that the chelate effect constants will depend on the following:

1. The metal ion involved.

2. The size of the chelate ring formed.

3. Whether or not the bidentate ligands assume a different configuration about the metal atom than the monodentate ligands.

4. Whether or not a resonance stabilized chelate ring is formed.

5. The number of bridges between the monodentate groups.

According to the validity of assumptions (a) and (b), the formation constant for the chelating agent may thus be expressed by combining the Edwards equation with (II), so that

$$
\log \mathrm{K}_{\mathrm{chel}}=\underline{\mathrm{X}} \underline{\beta \mathrm{pKa}}+\left[\mathrm{X} \underline{\alpha}(\mathrm{En}+1.74 \underline{\beta})+\log \mathrm{K}_{0}+\mathrm{x}\right]
$$

where pKa and En are properties of a monodentate group and are probably directly related to those of a similarly constituted bidentate ligand. The evaluation of $X$ and the relationship between pKa of a bi- and monodentate ligand should thus give the slope of the linear relationship, since all the bracketed terms are constant for similar ligands.

That a linear relationship would exist between reaction (3) and (4) may be arrived at by considering the Hammett plots for each of these two reactions. If reaction (3) involved $\mathrm{Cu}$ (II) and substituted pyridines, we may expect this set of equilibrium constants to give the Hammett plot. If reaction (4) involved $\mathrm{Cu}(\mathrm{II})$ and substituted bipyridines, a similar Hammett relationship would be expected. The $\log K_{3}$ and $\log K_{4}$ which are separately linear with the sigma values are thus linear with each other. The linear relationship thus expected for (3) and (4) must obey all restrictions placed on the Hammett relationship.

A comparison of the para sigma values and the formation constants of 5-substituted-1, 10-phenanthrolines (29) shows excellent agreement and supports the view that such agreement would also be found in bipyridines as well as pyridines. In fact, reaction (4) might just as well involve 1,10-phenanthrolines.

Table II-Correlation Between Formation and sigma Constants

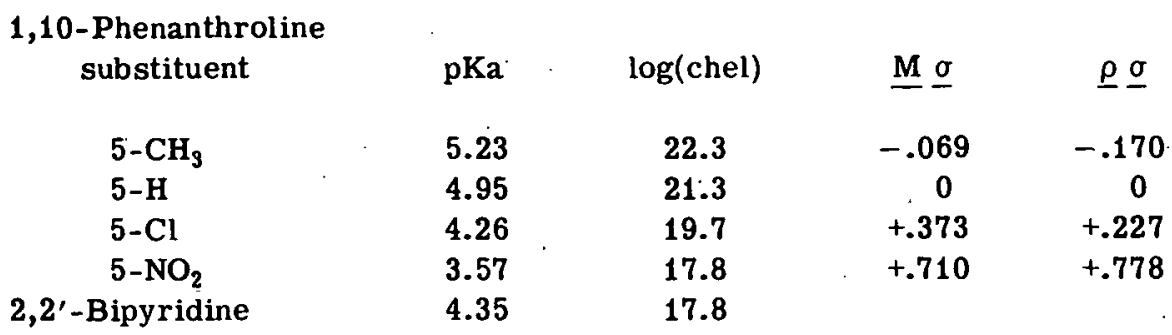

The relationship (III) would correlate only a. small number of chelating agents with the properties of simpler monodentate ligands and a chelate effect. Most chelating agents are not only unsymmetrical but cannot be considered as being built from a pair of monodentate ligands, and the properties of the "semi" bidentate ligand are nonexistent. However, it may be argued by analogy that the materials from which a chelate formation constant is built are common to all chelates and (III) merely expresses these factors in terms of simpler ligands, and may be translated into the terms of more complex ligands.

Salicylaldehydes and beta-diketones are examples of complex ligands, but the work of Calvin and Wilson (loc.cit) indicate $\log \mathrm{K}(\mathrm{chel})$ against pKa gives the same slope for each series of compounds but different intercepts. This, of course, is interpreted in terms of (III) that $\underline{X} \underline{\beta}$ is the same for each class or may be considered common for the group:

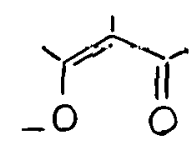


Different En values may account for the different intercepts. Whether the electrons of the ring are made available for the reaction

$$
2 A^{-}=A_{2}+2 e^{-}
$$

or for participation in resonance, these two explanations appear to be one in the same.

It was pointed out by Brandt and Wright (29) that bipyridyl did not follow the same relationship between log chelate constants and pKa of 1,10-phenanthrolines, with bipyridyl giving a less stable chelate than is expected from the pKa (see Table VI on page 23). This deviation may be explained by considering the free energy changes involved in the two reactions

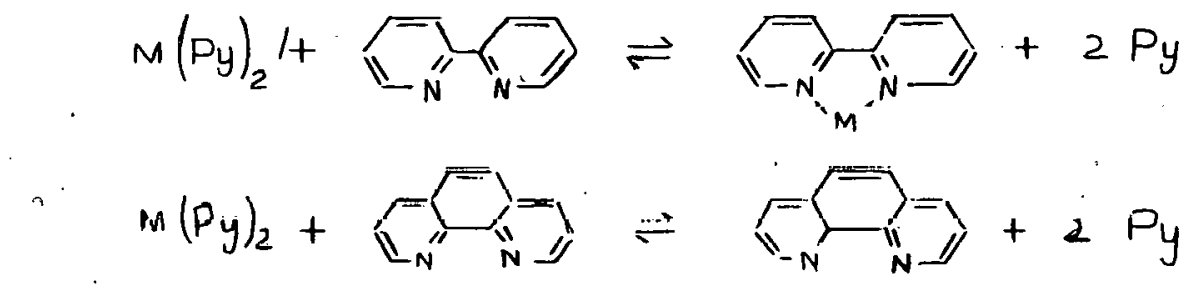

In the free energy expression for the second reaction, partition functions for rotation and vibration associated with the bond connecting the two rings are greatly diminished; however, in the products they appear to be about equal. This means a more positive entropy change for the second reaction and hence a tendency toward stabilization of the metal chelate. This would be reflected in the chi values of equation (III) since it would bear directly on the free energy relationship required by $X$ and $x$. It is unfortunate that suitably substituted bypyridyls are not available to further clarify this effect.

Van Uitert, Fernelius, and Douglas (30) have made a study of the effect of various end groups on the chelating properties of beta-diketones. They have found that the formation constants fall into three linear relationships with pKa of the ligand, each class unique in the number of ring end groups on the beta-diketones. Those containing methyl end groups have smaller chelating ability than a beta-diketone which has two ring systems as end groups. The data in Table III show this and the type of end groups involved.

\begin{tabular}{lccc}
\multicolumn{4}{c}{ Table III - Formation Constants of beta-Diketones } \\
\multicolumn{1}{c}{ Compound } & pKa & log & $K_{\text {Cu(chel) }}$ \\
& & & \\
2-Thenoylbenzoylmethane & 13.50 & 12.28 & 11.42 \\
Dibenzoylmethane & 13.75 & 12.98 & 12.00 \\
2-Furoylbenzoylmethane & 12.95 & 12.48 & 11.44 \\
Di-2-thenoylmethane & 12.63 & 12.23 & 11.28 \\
2-Thenoyl-2-furoylmethane & 12.30 & 11.92 & 10.01 \\
Benzoylacetone & 12.85 & 12.05 & 10.96 \\
Acetylacetone & 12.70 & 11.85 & 10.74 \\
2-Thenoylacetone & 12.35 & 11.70 & 10.68
\end{tabular}

The explanation given for this effect was that apparently a steric factor is operating. The methyl group is less effective than a ring group in shielding the metal ion from external contacts with the solvent. This explanation is not reasonable since the bulkier ring would also have more difficulty attaching itself to the metal by excluding more solvent from the metal atom.

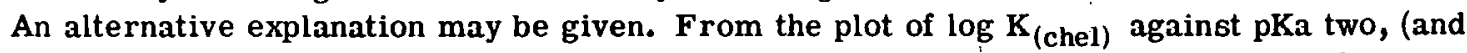
possible three) straight lines are obtained with each line corresponding to the number of ring end groups present. In terms of the modified Edwards equation this is interpretable on the 
basis of differing polarizabilities. That this property may differ from acetylacetone to dibenzoylmethane and may be revealed by considering the structures<smiles>CC1=C(C)C(=O)ONO1</smiles><smiles></smiles>

If these structures are important, phenylgroups on the one and three positions may greatly contribute to the stability of the chelate by structures such as

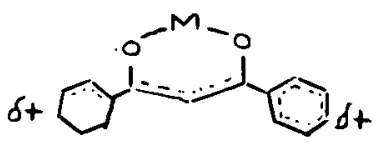

Furyl and thenyl groups have the same effect.

Irving and Rossotti (33) have reached the conclusion that the linear relationship between chelate constants and $\mathrm{pKa}$ will deviate when steric effects are involved. This is a result of their investigations on "the thermodynamic derivation of this and related equations (which) will be published shortly". Some of their conclusions are that for a given metal and a series of ligands of similar type, the plot of $\log \mathrm{K}_{1 \text { (chel) }}$ against $\mathrm{pKa}$ should be a straight line of unit slope; major deviations will occur when steric effects are involved and $\log K_{1 \text { (chel) }}$ will always be much smaller than predicted; minor deviations where $\log \mathrm{K}_{1(\mathrm{chel})}$ will be either slightly larger or smaller may also occur.

These authors present data which show that when substitution near the functional group<smiles>C=C(O)/C=C\C</smiles>

occurs, a change in the formation constant can be accounted for by steric or inductive effects which alter the basicity of either the oxygen or nitrogen. The compounds which deviated considerably from the predicted line of unit slope from the magnesium complexes were 8-hydroxy7-methylquinoline, 8-hydroxy-2-methylquinoline, 8-hydroxy-2, 4-dimethylquinazoline, and 8-hydroxy-4-methyl-2-phenyl-quinazoline.

Some confusion may result from these authors' treatment of the data. The pKa of the $\mathrm{OH}$ group was taken as a measure of the proton affinity for the entire molecule. Thus, for the 8-hydroxy-2-methylquinoline the inductive effect of the methylgroup increases the proton affinity of the nitrogen. The variable nitrogen basicity might just as well be included to avoid missing small steric effects.

Irving and Rossotti also argue that if, for a given cation, the stability of the complex depended only on the strength of the corresponding ligand-hydrogen bond, than a plot of log

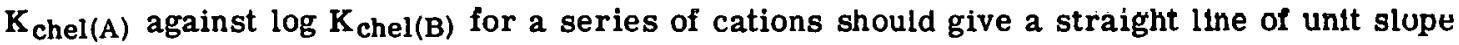
and of intercept equals $\mathrm{pKa}(\mathrm{A})-\mathrm{pKa}_{(B)}$, and they attribute departures from this linearity of unit slope and theoretical intercept to steric and other factors. Constants which demonstrated this linearity were $\log \mathrm{K}_{1}$ for the $\mathrm{Mg}(\mathrm{II}), \mathrm{Zn}(\mathrm{II}), \mathrm{Ni}(\mathrm{II}), \mathrm{UO}_{2}(\mathrm{II})$, and $\mathrm{Cu}(\mathrm{II})$ chelates of 8-hydroxyquinoline and $\log K_{1}$ for the corresponding metal chelates of 8-hydroxy-5-methylquinoline. When the corresponding constants for 8-hydroxycinnoline and 8-hydroxy-2-methylquinoline were plotted against the parent compound, serious deviations were noted. In the case of 8hydroxy-2-methylquinoline, deviations were attributed to steric interference of the methyl groups. In the case of 8 -hydroxycinnoline only the constant for the $\mathrm{Mg}(\Pi)$ complex fell on the theoretical line, and deviations became more serious as stability of the complexes increased. The authors attribute these deviations to "specific behavior" due to the low value of $\mathrm{pK}_{\mathrm{NH}}$ for 8-hydroxycinnoline. It was pointed out that this would be expected to reduce the stability of the $\mathrm{Cu}$ (II) complex and similar metals and have little or no effect on the $\mathrm{Mg}$ (II) complex.

According to the modified Edwards equation, the $\log \mathrm{K}_{\text {(chel) }}$ constants of two different ligands $A$ and $B$ and a series of metals may be treated as follows:

$$
\begin{aligned}
& \log \mathrm{K}_{\mathrm{chel}(\mathrm{A})}=\underline{\mathrm{X}} \underline{\beta} \mathrm{pKa}(\mathrm{A})+\underline{\mathrm{X}}\left(\underline{\left.\alpha \mathrm{En}_{(\mathrm{A})}+1.74 \underline{\beta}\right)+\log \mathrm{K}_{0}+\underline{\mathrm{x}}}\right. \\
& \log \mathrm{K}_{\mathrm{chel}(\mathrm{B})}=\underline{\mathrm{X}} \underline{\beta} \mathrm{pKa}_{(\mathrm{B})}+\underline{\mathrm{X}}\left(\underline{\alpha} \mathrm{En}_{(\mathrm{B})}+1.74 \underline{\beta}\right)+\log \mathrm{K}_{0}+\underline{\mathrm{x}}
\end{aligned}
$$


If chelate $A$ and $B$ are similar so that $\mathrm{En}_{(\mathrm{A})}$ equals $\mathrm{En}_{(\mathrm{B})}$ but differ greatly in pKa, then for any given metal

$$
\log \mathrm{K}_{\mathrm{chel}(\mathrm{A})}=\log \mathrm{K}_{\mathrm{chel}(\mathrm{B})}+\underline{\mathrm{X}} \underline{\beta}\left(\mathrm{pKa}_{(\mathrm{A})}-\mathrm{pKa}(\mathrm{B})\right) .
$$

This equation is in partial agreement with the statement of Irving only if beta is constant for all metals or if

$$
\mathrm{pKa}_{(\mathrm{A})}=\mathrm{pKa}_{(\mathrm{B})} \text {. }
$$

When the basicities of two ligands are equal or nearly so, a plot of $\log \mathbf{K}_{\text {chel(A) }}$ against $\log$ $\mathrm{K}_{\text {chel(B) }}$ will be a straight line of unit slope. This is true in the case of 8-hydroxy-2-methylquinoline and 8-hydroxy-5-methylquinoline where $\triangle \mathrm{pKa}$ as given by Irving is +0.31 . Unless $X$ $\underline{\beta}$ is very large, deviations from predicted linearity will be small or unnoticed. The 8-hydroxycinnoline complexes, however, do sliow devialions. In this case $\Delta \mathrm{pKa} 18-1.96$ where the $\underline{X} \underline{\beta}$ coefficients become important, and deviations due to varying either $X$ or $\underline{\beta}$ may show up here. The only two metals in Irving's study which have been assigned $\beta$ values are $\mathrm{ZnX}_{d}$ and $\mathrm{CuX}_{\boldsymbol{q}}$, being $0.65 \mathrm{U}$ and $\mathrm{U.y58}$, respectively. On this basis it is understandable why Irving found $\mathrm{Cu}$ (II) complexes to give greater deviation than $\mathrm{Zn}(\mathrm{II})$ complexes.

Similar deviations were found for the chelating agents listed in Table IV. The $\triangle \mathrm{pKa}$ refers to the difference between these reagents and 8-hydroxyquinoline.

Table IV-Correlations of Formation Constants of Oximes

\section{Compound}

8-hydroxy-2-methylquinoline

8-hydroxy-5-methylquinoline

8-hydroxycinnoline

8-hydroxyquinazoline

5-hydroxyquinoxaline

8-hydroxy-4-methylcinnoline
$\Delta \mathbf{p K a}$

Deviations

$+0.21$

$+0.30$

$-1.96$

$-1.21$

$-1.51$

$-1.80$ yes

no

yes

yes

yes

yes

\section{EXPERIMENTAL}

Preparation of Materials

Preparation of beta-diketones

Diisobutyrylmethane and dipivaloylmethane (DPM) were prepared by condensing the appropriate ester and ketone, using sodamide as the condensing agent, according to the procedure of Hauser and Adams (31).

Dipivaloylmethane was identified by the melting point of its $\mathrm{Cu}$ (II) chelate 190 to $191^{\circ}$.* The fraction of the liquid boiling 94.0 to $94.6^{\circ} \mathrm{zo} \mathrm{mm}$. was saved after distillaliun Llurugh a center rod column. Diisobutyrylmethane which was not previously prepared by this method gave a $\mathrm{Cu}$ (II) chelate melting 127 to $129^{\circ}$. The fraction boiling at 80.5 to $81.4^{\circ}$ at $17 \mathrm{~mm}$. was saved.

Anal. Calcd. for $\mathrm{C}_{9} \mathrm{H}_{18} \mathrm{O}_{2}$ : C 69.21; $\mathrm{H}, 10.32$. Found: $\mathrm{C}, 69.5 ; \mathrm{H}, 10.2$.

Acetylacetone (Eastman Kodak Co.) was purified by fractionation. The middle fraction boiling at $127^{\circ}$ was used in all cases.

3-Methylacetylacetone was prepared by acid catalized condensation of acetic anhydride with ethylmethylketone, according to the procedure of Hauser (32). The fraction boiling $75.0^{\circ}$ at $30 \mathrm{~mm}$. was used for infrared and ultraviolet absorption measurements.

*All melting points and boiling points in this section are uncorrected. 
Preparation of reagents

Dioxane was purified by refluxing with dilute hydrochloric acid, drying over potassium hydroxide and flash distilled from sodium metal, according to the procedure used by Calvin and Wilson (6). It was fractionated immediately before use.

Standard potassium hydroxide in mixed solvents. The most convenient method for preparing carbonate free base without introducing foreign materials such as barium chloride or base exchange resins was by adding clean pieces of potassium metal (about two grams) to a bottle containing $750 \mathrm{ml}$. of pure dioxane under a nitrogen atmosphere. The bottle was then sealed with a stopper equipped with nitrogen inlet and outlet and a small addition funnel. Water was cautiously added to the dioxane as nitrogen passed through the system. After the potassium metal had all dissolved, enough water was added to give the solvent the desired percentage. Vigorous shaking was usually required to form a homogeneous solution. The solution was then stored under nitrogen.

Potassium perchlorate which was used as the inert electrolyte in the potentiometric titrations was reagent grade, but it was found necessary to recrystallize it from water at least once to free it of undesirable acidic components.

Metal perchlorates were reagent grade (G. F. Smith). Stock solutions were prepared of approximately 0.0125 molar.

\section{Infrared and Ultraviolet Spectra}

Infrared absorption spectra

Pure liquids of acetylacetone, diisobutyrylmethane, dipivaloylmethane, and 3-methylacetylacetone were used in a capillary cell on a Baird spectrophotometer. These spectra are shown in Figures 3 and 4. The liquids were used without further purification. Samples of dipivaloylmethane were also used to obtain high resolution spectra in the 3 to 5 micron region, using the Perkin Elmer Model 13 with lithium fluoride prisms. This and other high resolution spectra, including the copper chelate of DPM, are reproduced in Figure 5.

Deuterated samples of acetylacetone and dipivaloylmethane were prepared by the ion exchange method. The acetylacetone was dissolved in sodium deuteroxide solution which was then acidified with deutero sulfuric acid. The acetylacetone which separated from the aqueous layer was removed and dried over calcium chloride. Since the sodium salt of dipivaloylmethane was insoluble in the basic solution, it was dissolved in ether and shaken with this solution. The ether solution was then separated and shaken with deutero sulfuric acid solution. The ether was dried and evaporated from the deuterated dipivaloylmethane which was then fractionated. The spectras are shown in Figure 2. Samples of acetylacetone and dipivaloylmethane were treated in the same way as described above except sodium hydroxide and sulfuric acid were used. Infrared spectra were found to be identical with those previously taken on the undeuterated compounds.

Lithium chelate of dipivaloylmethane was prepared by shaking a $0.1 \mathrm{~N}$ solution of DPM in ether with a $2 \mathrm{~N}$ solution of lithium hydroxide. The solutions were separated and evaporation of the ether yielded white chelate. A sample was used to obtain the infrared spectrum given in Figure 4 without further purification.

Ultraviolet absorption spectra

All were taken with a Beckman model DU spectrophotometer with the cell compartment thermostated at $25^{\circ}$. Square one $\mathrm{cm}$. cells were usually used except when it was necessary to keep the solution in the cell for long periods of time, in which case the one cm. cylindrical cells were used.

Cyclohexane and acetonitrile were the only two solvents used which required purification by distillation. Isooctane (Phillips) and absolute ethanol required no purification. The water used was "de-ionized" through an ion exchange column (Barnstead Bantam).

The absorption curves are summarized in Table V. The solutions were prepared by accurately weighing out $1 \times 10^{-3}$ moles of the purified compounds and dissolving them to form 


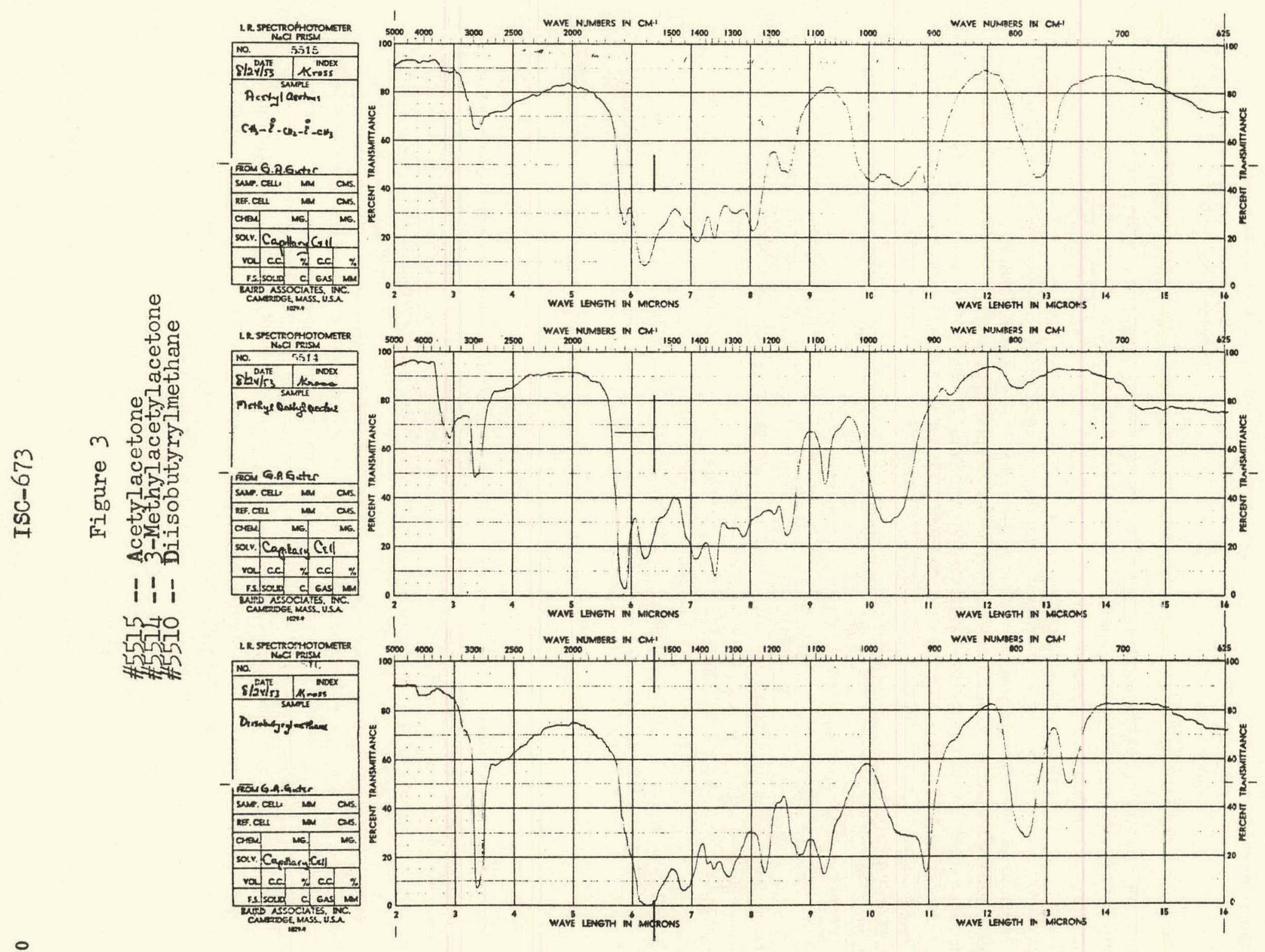




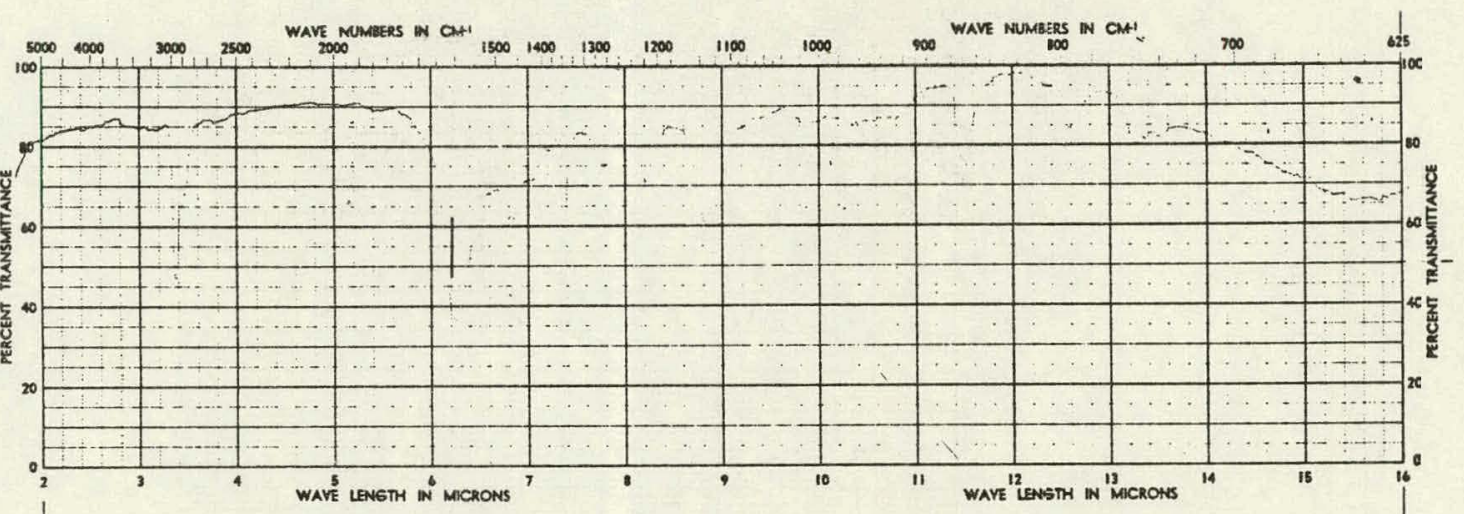

LR SECCROMHOTONATER 1

Ware

10.

$3-12-54$ inedges

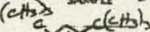

Lidenitive t

divintorit

row 6 cater

ar.cert an ans

का

sav. Nuriol mall

val ac is ac.

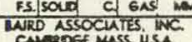

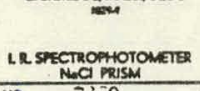

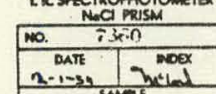

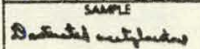

$\left[\mathrm{Cu}_{2}-1\right] \mathrm{Cx}_{2}$

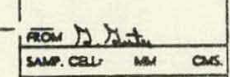

whe cal on as as

areal $w$

sav. Coith wase

rac ace. $2 . \mathrm{ce}$.

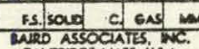

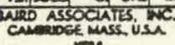
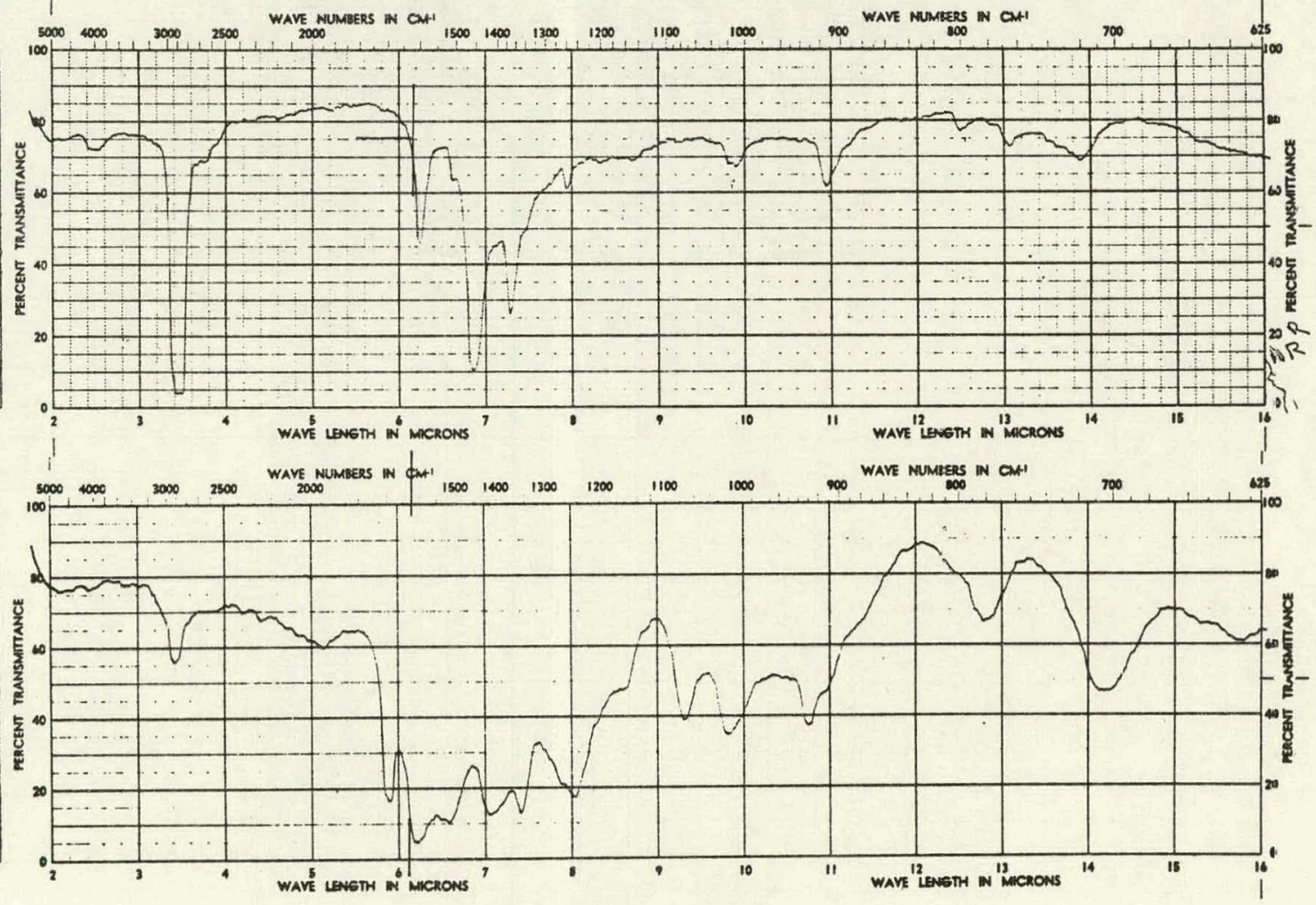

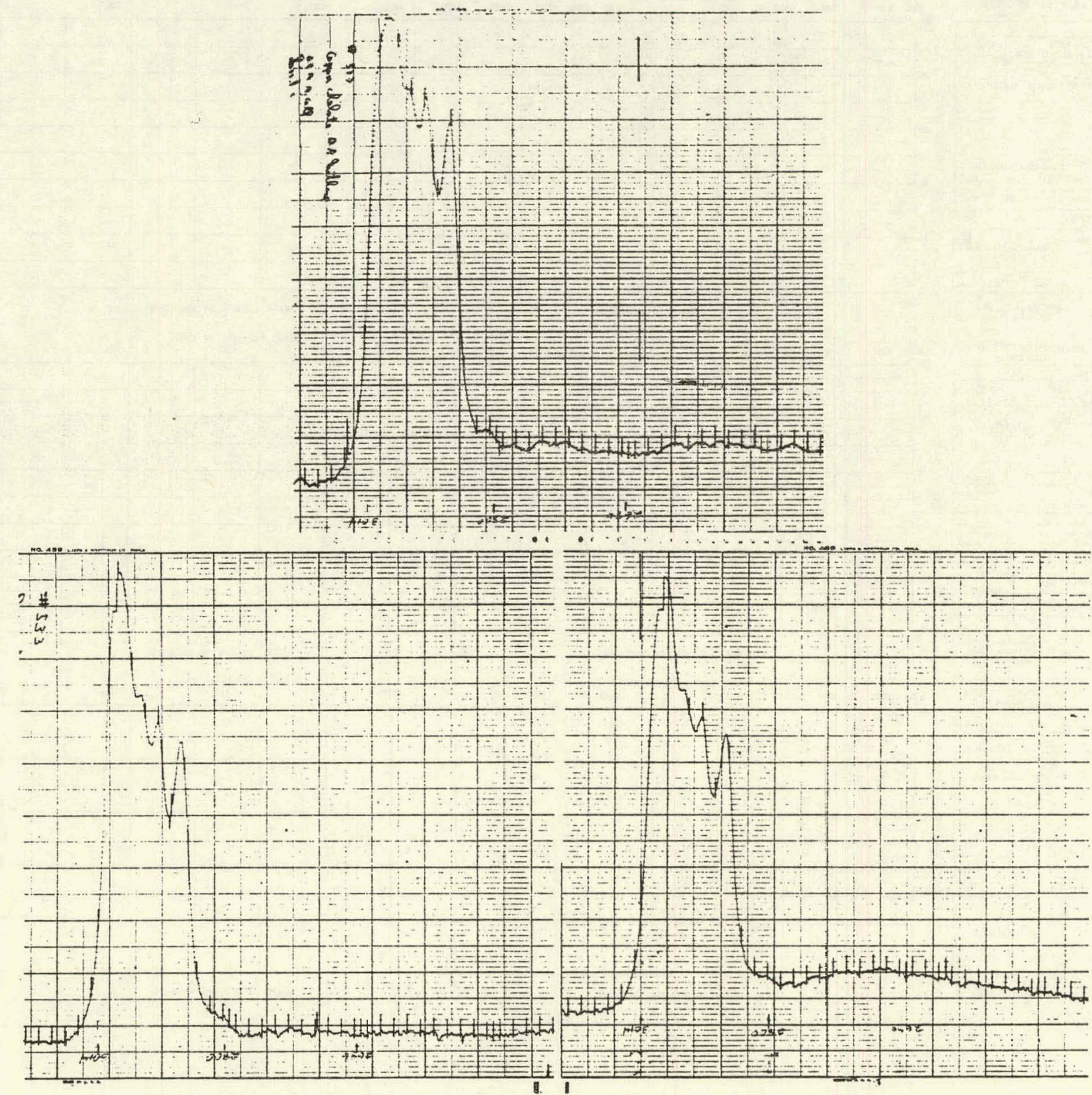

$\frac{2}{4}$

要 
$100 \mathrm{ml}$. of solution. This solution was then diluted one hundred fold to obtain solutions which: absorbed in the range of the spectrophotometer. When water solutions of diisobutyrylmethane or dipivaloylmethane were required, a stock solution of ethanol was diluted one hundred fold with water.

Table V-Ultraviolet Absorption of beta-Diketones

\begin{tabular}{llcr} 
Compound & \multicolumn{1}{c}{ Solvent } & Max. $(\mathbf{m} \mu)$ & $\begin{array}{r}\text { Extinction } \\
\text { coefficient }\end{array}$ \\
& Acetonitrile & 273 & $0.63 \times 10^{4}$ \\
ylacetone & Isooctane & 271 & $0.99 \times 10^{4}$ \\
ylacetone & Water & 274 & $0.15 \times 10^{4}$ \\
ylacetone & NaOHaq. & 294 & $2 \times 10^{4}$ \\
ylacetone & Acetonitrile & 274 & $0.71 \times 10^{4}$ \\
butyrylmethane & Cyclohexane & 274 & $1.11 \times 10^{4}$ \\
obutyrylmethane & Water & 274 & $0.16 \times 10^{4}$ \\
butyrylmethane & Acetonitrile & 276 & $1.09 \times 10^{4}$ \\
aloylmethane & Isooctane & 274 & $1.27 \times 10^{4}$ \\
Ealoylmethane & Excess NaOH & 294 & $1.81 \times 10^{4}$ \\
Waloylmethane & Water & 278 & $0.18 \times 10^{4}$
\end{tabular}

Kinetics of Equilibration

The absorbances at the peaks of the ultraviolet spectra were compared with the known percent of enol content for each solvent. A direct relationship was observed as shown in Table VI. This data is plotted in Figure 6

Stock solutions of the diketones were prepared in ethanol with a concentration of $1 \times 10^{2}$ molar. One ml. of a stock solution was added to water which had been brought to $25^{\circ}$ and the

Table VI-Absorbance of Acetylacetone and Enol Content

\begin{tabular}{lcccc}
\multicolumn{1}{c}{ Solvent } & Absorbance of $1 \times 10^{-4} \mathrm{~m}$. solution & \multicolumn{2}{c}{$\%$ Enol } \\
Water & & & \\
Acetoniltile & $:$ & 0.150 & $15.5(34)$ \\
Chloroform & 0.600 & 58 & $(35)$ \\
Cyclohexane & 0.900 & 78 (35) \\
\hline
\end{tabular}

resulting solution was diluted to $100 \mathrm{ml}$. A sample of this diluted solution was rapidly placed in a quartz cell and inserted in the thermostated cell compartment of the spectrophotometer. The spectrophotometer had been previously balanced at the wavelength of the peak of the particular compound. The absorbence at this wavelength was then read at convenient time intervals. In the case of acetylacetone the operations had to be performed very rapidly and a habit formed before enough data could be obtained from a single run. The data was treated as follows:

$$
\begin{aligned}
\mathbf{A} & =\text { Absorbance at enol peak } \\
\epsilon & =\text { Extinction coefficient of enol form } \\
\mathbf{E} & =\text { Concentration of enol form } \\
\mathbf{K} & =\text { Concentration of keto form } \\
\mathrm{k}_{1} & =\text { Rate constant for ketonization } \\
\mathrm{k}_{2} & =\text { Rate constant for enolization } \\
\mathbf{C} & =\mathbf{E}+\mathbf{K} \\
\mathbf{E} &
\end{aligned}
$$




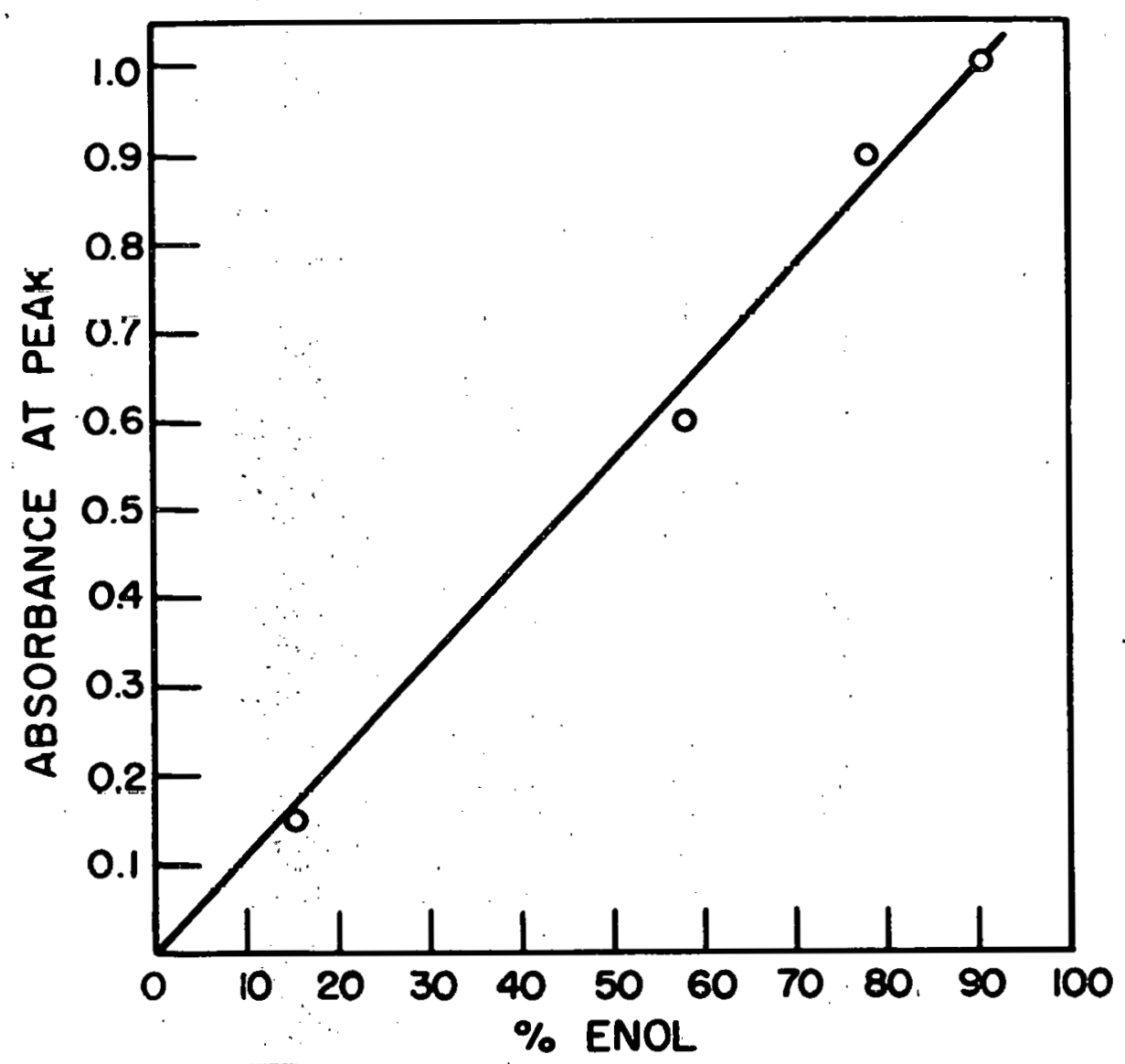

Fig. 6-Comparison of spectrophotometric data with known enol content of acetylacetone. 


$$
\begin{aligned}
& \frac{-d E}{d t}=k_{1} E-k_{2} K \\
& \frac{-d E}{d t}=\left(k_{1}+k_{2}\right) E-k_{2} C
\end{aligned}
$$

since $\mathbf{A}=\epsilon \mathbf{E}$

$$
\frac{-d A}{d t}=\left(k_{1}+k_{2}\right) A-\epsilon k_{2} C
$$

The slope $\mathrm{dA} / \mathrm{dt}$ was found by the mirror method and plotted against $A$. The best straight line was drawn for these points and the slope gave $k_{1}+k_{2}$. The value of $\epsilon$ for acetylacetone was calculated from the data in Table VII. For diisobutyrylmethane and dipivaloylmethane $\epsilon$ was calculated from the absorbance in the lease polar solvent, assuming that these compounds are 100 percent enulized in these solvents as shown by the infrared absorption spectra of the pure liquids. The results are given in Table VII.

\section{Extraction of Alkali Metal Ions with Dipivaloylmethane}

Extraction experiments were performed using an ether (reagent grade) solution of dipivaloylmethane, which was shaken with an aqueous solution of the alkali metal ion in a small glass

\begin{tabular}{|c|c|c|c|}
\hline Compound & $\mathbf{k}_{1} \dagger$ & $\mathbf{k}_{2} \dagger$ & $k_{2} / k_{1}$ \\
\hline Acetylacetone & 917 & 143 & 0.156 \\
\hline Diisobutyrylmethane & 285 & 48 & 0.167 \\
\hline Dipivaloylmethane & 47.2 & 7.8 & 0.165 \\
\hline
\end{tabular}
stoppered addition funnel. After the layers separated, an aliquot of the ether phase was withdrawn and titrated to determine the amount of alkali metal chelate extracted.

The tirations werc carriod out by either of twn methnds, using a micro buret calibrated to $0.01 \mathrm{ml}$. in each case. For the non-aqueous titrations an aliquot of the ether layer was mixed with an equal volume of glacial acetic acid and titrated with perchloric acid in dioxane, standardized with potassium acid phthalate dissolved in acetic acid. Methyl violet was used as an indicator but good end-points were not obtained at high chelate concentrations. For the aqueous titrations an aliquot of the ether layer was shaken with an equal volume of water and the mixture was titrated with standard hydrochloric acid. Thymol blue was used as the indicator with the change from green to yellow heing taken as the end-point. The extraction experiments are summarized in Table VIII, and some are shown graphically in Figure 7.

A suitable procedure for the determination of lithium in the presence of potassium and sodium was found to be as follows: One ml. of a solution $0.500 \mathrm{~N}$ in $\mathrm{Li}^{+}, 0.5 \mathrm{~N}$ in $\mathrm{Na}^{+}$, and $1.0 \mathrm{~N}$ in potassium hydroxide in a small separatory funnel for two minutes with $50.0 \mathrm{ml}$. of $0.1 \overline{\mathrm{N}}$ dipivaloylmethane in ether. A $25.0 \mathrm{ml}$. aliquot of the ether solution was mixed with an equal volume of water and titrated with $0.1000 \mathrm{~N}$ acid. A total of four such extractions was carried out on four, one ml. samples of the lithium solution; each time as much as possible of the aqueous layer was saved and the four of them were combined. Two ml. of the combined aqueous layers were treated separately with the reagent as above and the aqueous layers again combined. One ml. of the last combined aqueous layers was again treated to obtain a blank titer. The results are given in Table IX. 


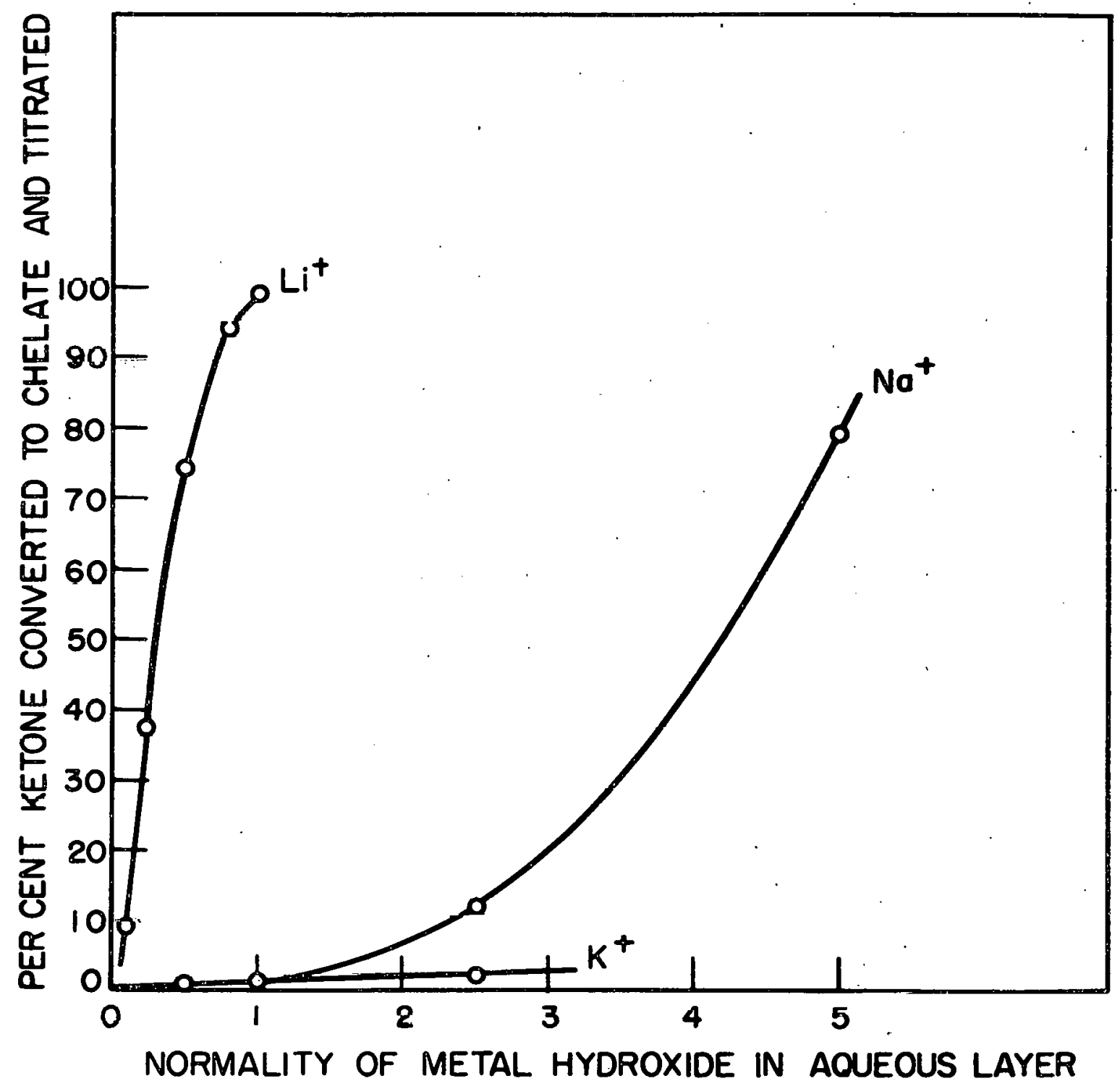

Fig. 7-Summary of extraction experiments. Equal volumes of the ether and aqueous layers were used. The concentration of DPM was $0.1 \mathrm{~N}$. 
Table VII - Extraction of Alkali Metal Ions with 0.1N Dipivaloylmethane in Ether

\begin{tabular}{|c|c|c|c|c|c|c|c|}
\hline \multirow[b]{2}{*}{$\mathrm{K}^{+}$} & \multicolumn{3}{|c|}{$\begin{array}{l}\text { Initial }_{s} \text { concentrations } \\
\text { in water layer }\end{array}$} & \multirow{2}{*}{$\begin{array}{c}\text { Vol. } \\
\text { ether } \\
\text { layer } \\
\mathrm{ml} .\end{array}$} & \multirow{2}{*}{$\begin{array}{c}\text { Vol. } \\
\text { water } \\
\text { layer } \\
\mathrm{ml} .\end{array}$} & \multirow{2}{*}{$\begin{array}{c}\text { Aliquot } \\
\text { of ether } \\
\text { titrated } \\
\mathrm{ml} .\end{array}$} & \multirow{2}{*}{$\begin{array}{l}0.1 \mathrm{~N} \\
\text { acid } \\
\text { titer }\end{array}$} \\
\hline & $\mathrm{Na}^{+}$ & $\mathrm{Li}^{+}$ & $\mathrm{OH}^{-}$ & & & & \\
\hline $0.5 \underline{N}$ & - & - & $0.5 \mathrm{~N}$ & 25.0 & 25.0 & 20 & 0.07 \\
\hline- & - & 0.5 & $0.5^{-}$ & 25.0 & 25.0 & 20 & 14.19 \\
\hline - & 0.5 & - & 0.5 & 25.0 & 25.0 & 20 & 00.10 \\
\hline - & - & 1.0 & 1.0 & 25.0 & 25.0 & 20 & 19.82 \\
\hline - & 1.0 & - & 1.0 & 25.0 & 25.0 & 20 & 0.30 \\
\hline - & 2.5 & - & 2.5 & 25.0 & 25.0 & 20 & 2.46 \\
\hline - & 5.0 & - & 5.0 & 25.0 & 25.0 & 20 & 15.83 \\
\hline - & - & 0.75 & 0.75 & 10.0 & 10.0 & 5.0 & 4.75 \\
\hline - & - & 0.25 & 0.25 & 10.0 & 10.0 & 5.0 & 1.88 \\
\hline - & - & 0.1 & 0.1 & 10.0 & 10.0 & 5.0 & 0.46 \\
\hline 2.5 & - & - & 2.5 & 10.0 & 10.0 & 5.0 & 0.12 \\
\hline 1.0 & - & - & 1.0 & 10.0 & 10.0 & 5.0 & 0.03 \\
\hline 1.0 & - & 1.0 & 1.0 & 10.0 & 10.0 & 5.0 & 4.86 \\
\hline 1.0 & - & 0.5 & 1.0 & 10.0 & 10.0 & 5.0 & 4.65 \\
\hline 1.0 & - & 0.2 & 1.0 & 10.0 & 10.0 & 5.0 & 3.73 \\
\hline 1.0 & - & 0.05 & 1.0 & 10.0 & 10.0 & 5.0 & 1.12 \\
\hline 1.0 & - & 0.025 & 1.0 & 10.0 & 10.0 & 5.0 & 0.54 \\
\hline 1.0 & 1.0 & - & 1.0 & 10.0 & 10.0 & 5.0 & 0.08 \\
\hline 1.0 & 0.5 & - & 1.0 & 10.0 & 10.0 & 5.0 & 0.05 \\
\hline 1.0 & - & - & 1.0 & 10.0 & 10.0 & 5.0 & 0.02 \\
\hline 1.0 & 2.4 & - & 1.0 & 10.0 & 10.0 & 5.0 & 0.14 \\
\hline 1.0 & - & 1.0 & 1.0 & 50.0 & 1.00 & 25.0 & $4.48^{*}$ \\
\hline 1.0 & - & 1.0 & 1.0 & 50.0 & 1.00 & 25.0 & $4.42 \dagger$ \\
\hline 1.0 & - & 1.0 & 1.0 & 50.0 & 1.00 & 25.0 & 4.41 \\
\hline 1.0 & - & 0.5 & 1.0 & 50.0 & 1.00 & 25.0 & 2.67 \\
\hline
\end{tabular}

Table IX-Determination of 0.500 N Solutions of Lithium Ion*

Vol. of $0.0928 \mathrm{~N}$ acid required for titer 1st extraction 2nd extraction

0.262

0.265

2.846

2.875

2.861
3 rd extraction

0.239

0.480

0.491

0.491

* Prepared using lithium carbonate as the primary standard and dissolving in an equivalent amount of $\mathrm{HCl}$. 


\section{Spectrophotometric Measurements of Acid Dissociation Constants}

Method

By measuring the absorbance, $A$, due to the ionized $\mathrm{K}^{-}$and unionized $\mathrm{KH}$ species, it is possible to calculate an equilibrium constant, $K_{i}$, if the extinction coefficients of each species are known.

$$
\begin{aligned}
& \mathrm{A}=\epsilon_{\mathrm{KH}}[\mathrm{KH}]+\epsilon_{\mathrm{K}^{-}}\left[\mathrm{K}^{-}\right] \\
& \mathrm{C}=\left[\mathrm{K}^{-}\right]+[\mathrm{KH}] \\
& \mathrm{K}_{\mathbf{i}}=\frac{\left[\mathrm{K}^{-}\right]}{[\mathrm{KH}]\left[\mathrm{OH}^{-}\right]}
\end{aligned}
$$

If

$$
\mathrm{K}_{\mathrm{w}}=\left[\mathrm{OH}^{-}\right]\left[\mathrm{H}^{+}\right]
$$

then

$$
\mathbf{K}_{\mathbf{a}}=\mathbf{K}_{\mathbf{e}} \times \mathbf{K}_{\mathbf{w}}
$$

For very weak acids the extinction coefficient, $\epsilon_{\mathrm{KH}}$, may be measured from the absorbance of a neutral solution. The value for $\epsilon_{\mathrm{K}}{ }^{-}$may only be estimated from a solution of the weak acid highly concentrated in $\mathrm{OH}^{-}$. The value for $\mathrm{K}_{\mathrm{W}}$ in mixed solvents was interpolated from data given by Harned and Owen (36).

Diplvaloylmethane in 50\% dioxane.

The absorbance of each solution was read at $294 \mathrm{~m} \mu$ where the extinction coefficient for the unionized species was measured as $0.469 \times 10^{4}$. The total consentration of all sneries of the diketone was $1.00 \times 10^{-4}$ molar in each case. The ion product for water in 50 percent dioxane was taken as $2.8 \times 10^{-16}(36)$ at ionic strength of 0.01 molar. The results of four determinations were the following:

$$
\begin{aligned}
\mathrm{K}_{\mathbf{i}} & =212 \\
\mathrm{~K}_{\mathbf{i}} & =213 \\
\mathrm{~K}_{\mathbf{i}} & =205 \\
\mathrm{~K}_{\mathbf{i}} & =\mathbf{2 1 9} \\
\text { average } & \mathbf{2 1 2} \\
\text { pKa } & =\mathbf{1 3 . 2 3}
\end{aligned}
$$

\section{Dipivaloylmethane in water}

The absorbances were read at $294 \mathrm{~m} \mu$ where the extinction coefficient for the unionized species was measured as $0.113 \times 10^{4}$ and the constant for the anion was estimated $1.93 \times 10^{4}$. A Etock colution of the dikctone was prepared in etlianul and diluled une hundred fold with water when used. The ionic strength was held at 0.01 molar with tetramethylammonium bromide. The $\left[\mathrm{OH}^{-}\right]$used and the results are given in Table $\mathrm{X}$.

\section{Diisobutyrylmethane in water}

The absorbances were read at $295 \mathrm{~m} \mu$ where the extinction coefficients for the unionized species were measured as $0.108 \times 10^{4}$ and estimated as $2.03 \times 10^{4}$ for the anion. 
Table X-Determination of pKa of Dipivaloylmethane

\begin{tabular}{ccc}
{$\left[\mathrm{OH}^{-}\right] \times 10^{4}$} & $\mathrm{~K}_{\mathrm{i}} \times 10^{2}$ & $\mathrm{pKa}$ \\
5.0 & 1.40 & 11.85 \\
10 & 1.73 & 11.76 \\
15 & 1.68 & 11.77 \\
20 & 1.83 & 11.74 \\
25 & 1.84 & 11.74 \\
50 & 1.79 & 11.75 \\
99 & 1.55 & 11.81 \\
\multicolumn{2}{c}{ average 11.77}
\end{tabular}

Potentiometric Measurement of Formation Constants

Apparatus

The titrations were carried out in a jacketed beaker having a capacity of about $250 \mathrm{ml}$. The stopper of the beaker contained nitrogen inlet and outlet, a delivery tube through which the titrant was added, and a stirring apparatus. The micro buret used for measuring out the titrant had a five ml. capacity and could be read to $0.001 \mathrm{ml}$. Titrations were followed with a Beckman model G pH meter.

\section{Calibration of $\mathrm{pH}$ meter}

Due to the difficulty in obtaining the true value for hydrogen ion activity from the $\mathrm{pH}$ meter in mixed solvents, the $\mathrm{pH}$ meter was used to read hydrogen ion concentration, and the constants which were obtalned are relative concentration constants (37).

The $\mathrm{pH}$ meter was standardized against Beckman buffer solution at $\mathrm{pH}$ 7.00. One hundred $\mathrm{ml}$. of 75 percent dioxane, 0.6925 grams of potassium perchloraté and one $\mathrm{ml}$. of $0.1 \mathrm{~N}$ perchloric acid placed in the titration vessel and stirred until the potassium perchlorate had dissolved. The mixture was titrated with $0.05 \mathrm{~N}$ potassium hydroxide in 75 percent dioxane, adding about $0.1 \mathrm{ml}$. each time. Making allowance for volume changes, the hydrogen ion concentration, $\left[\mathrm{H}^{+}\right]$, was calculated and plotted against the reading of the $\mathrm{pH}$ meter. A similar plot of $\left[\mathrm{OH}^{-}\right]$against the $\mathrm{pH}$ meter readings was made for the basic side of the titration. Both plots were placed on the same graph and adjusted until they both fell on the same straight line. A slope of 1.00 was obtained which indicated a near perfect Nernst slope. It was also found that $\left[\mathrm{H}^{+}\right]$equal $\mathrm{pH}$ meter reading plus 0.37 . The plot also gave the value for the $\mathrm{pKw}$ of water in this solvent mixture to be 16.87 .

\section{Acid dissociation constants of the diketones}

The acid dissucialion conslants were obtained from the half equivalence points on the potentiometric titration curves. Correction had to be made to the reading obtained for dipivaloylmethane due to its very weak acidic nature and because the dilute solutions used promoted hy drolysis of the anion. The values obtained in 75 percent dioxane 0.05 molar potassium perchlorate are as follows:

$\begin{array}{ll}\text { Acetylacetone } & \mathbf{1 1 . 2 7} \\ \text { Diisobutyrylmethane } & 12.48 \\ \text { Dipivaloylmethane } & 14.48\end{array}$

Potentiometric titrations with metal ions and chelating agents

The measurement of formation curves by the potentiometric method is possible if the following reactions occur. 


$$
\begin{aligned}
& \mathbf{M}^{++}+\mathbf{A}^{-} \stackrel{\mathbf{K}_{1}}{=} \mathbf{M A}^{+} \\
& \mathbf{M A}^{+}+\mathbf{A}^{-} \stackrel{\mathbf{K}_{2}}{=} \mathbf{M A}_{2}
\end{aligned}
$$

In such a case $K_{1}$ and $K_{2}$ can be calculated in the usual manner from the formation function.

$$
\bar{n}=\frac{K_{1} A+2 K_{1} K_{2} A^{2}}{1+K_{1} A+K_{1} K_{2} A^{2}}
$$

$A$ is the molar concentration of the chelating agent with all ionizable protons removed. In the potentiometric method the formation function is easily calculated from $\left[\mathrm{H}^{+}\right]$measurements since

$$
\overline{\mathbf{n}}=\frac{[\text { chelated ligands }]}{[\text { total metal }]}=\frac{\left[\mathrm{H}^{+} \text {liberated }\right]}{[\text { total metal }]}
$$

If, however, hydrolysis of the monochelate or of the aqueous metal ion occurs as in the following reactions:

$$
\begin{aligned}
& \mathrm{M}^{++}+\mathrm{OH}^{-}=\mathrm{MOH}^{+} \\
& \mathrm{MOH}^{+}+\mathrm{OH}^{-}=\mathrm{M}(\mathrm{OH})_{2} \\
& \mathrm{MA}^{+}+\mathrm{OH}^{-}=\mathrm{MAOH}
\end{aligned}
$$

it is no longer possible to calculate $\bar{n}$, since

$$
\left[\mathrm{H}^{+} \text {liberated }\right] \neq[\text { chelated ligands }] \text {. }
$$

Also some of the metal has been removed in the form of the hydrolyzed products. In order to account for the hydrolysis we may still use the potentiometric data and define a new formation function. Brackets are omitted in the following equations:

$$
\begin{aligned}
& \overline{\mathrm{q}}=\frac{\text { bound ligand }+ \text { bound } \mathrm{OH}^{-}}{\text {total metal }}=\frac{\mathrm{H}^{+} \text {liberated }}{\text { total metal }} \\
& \overline{\mathrm{q}}=\frac{\mathrm{MA}+2 \mathrm{MA}_{2}+2 \mathrm{MAOH}+\mathrm{MOH}+2 \mathrm{M}(\mathrm{OH})_{2}}{\mathrm{M}+\mathrm{MA}+\mathrm{MA} \mathrm{A}_{2}+\mathrm{MAOH}+\mathrm{MOH}+\mathrm{M}(\mathrm{OH})_{2}}
\end{aligned}
$$

since

$$
K_{1}=\frac{M A}{M A A} ; K_{y}=\frac{M A_{2}}{M A A} ; K_{3}=\frac{M A O H}{M A \cdot O H} ; K_{d}=\frac{M O H}{M O H} ; K_{6}=\frac{M(O H)_{2}}{M O H O H}
$$

then

$$
\bar{q}=\frac{K_{1} A+2 K_{1} K_{2} A^{2}+2 K_{1} K_{3} A(O H)+K_{4}(O H)+2 K_{4} K_{5}(O H)^{2}}{1+K_{1} A+K_{1} K_{2} A^{2}+K_{1} K_{3} A(O H)+K_{4}(O H)+K_{4} K_{5}(O H)^{2}}
$$

Although the exact value of $\bar{q}$ may be determined from potentiometric data if $\mathrm{pKa}$ of the diketone is large, it is not possible to calculate the concentration of $A$ so that a formation curve may be obtained. If, however, a large excess of $\mathrm{AH}$ is used so that [AH] remains practically constant, A may be calculated. Under these conditions chelation may occur at a low $\mathrm{pH}$ where the relative errors of $\left[\mathrm{H}^{+}\right]$measurements are large and $\overline{\mathrm{q}}$ can not be accurately measured. 
Since it is not possible to solve for the exact value of $K_{1}$ and $K_{2}$ if hydrolysis occurs, they were obtained assuming that no hydrolysis did occur. Further titrations were then carried out with greater [AH]. This effectively gave a formation curve at lower.pH's or gave less weight to the hydrolysis terms. These values of $K_{1}$ and $K_{2}$ were then compared with the first values obtained. If they varied outside of experimental error, $\pm .05 \log \mathrm{K}$.units, and in a regular manner, hydrolysis was considered to be important and formation constants could not be obtained.

\section{Titration procedure}

Two to four ml. of the metal ion stock solution of about 0.0125 molar were placed in a titration vessel with 0.6925 grams of potassium perchlorate, five to fifty ml. of $1 \times 10^{-2}$ molar diketone dissolved in dioxane, and enough water and dioxane to bring the total volume to $100 \mathrm{ml}$. of 75 percent in dioxane. This mixture was stirred and nitrogen passed through the vessel throughout the titration. After all the potassium perchlorate had dissolved, the titration was started, readings being taken at about every $0.10 \mathrm{ml}$. and as close as possible near the end points.

\section{Formation constants of $\mathrm{Zn}$ (II) and $\mathrm{Fe}$ (II) chelates}

In order to estimate the extent of hydrolysis of the metals in 75 percent dioxane, each metal was titrated alone. In most cases precipitation occurred and no definite results could be obtained. Charles and Freiser (38) have shown that the end point obtained corresponded to exactly two equivalents of hydrogen liberated for one mole of bivalent metal ion. When ferrous ion was titrated two end points were obtained, indicating the presence of ferric ion or a strong acid im purity. Measurements were, therefore, not attempted.

Titrations of zinc ion with varying amounts of chelating agents indicated that hydrolysis was important. Although formation curves are tabulated for $\mathrm{Zn}(\mathrm{II})$. chelates, no values for the formation constants were assigned.

\section{Calculation of formation curves}

The formation curves which are tabulated in this section were calculated by the method of Calvin and Wilson (6). The formation constants reported are taken from the formation curves at points where $\bar{n}=0.5$ and 1.50 . In some cases where it was not possible to calculate the formation curve at $\overline{\mathbf{n}}=0.5$, the value for $\log \mathrm{K}_{1} \mathrm{~K}_{2}$ was taken from the point where $\overline{\mathbf{n}} \cdot \mathbf{1 . 0 0}$. The formation curves are given in Table XII to XLI, and a summary of the formation constants is given in Table XLII.

Spectrophotometrie Estimation of Formation Constants in 50 Percent Dinxane

Lithium chelate of dipivaloylmethane

The extinction coefficient for the lithium chelate of dipivaloylmethane was taken to be equal to the extinction coefficient of the anion since there was no change in the absorption at the anion peak when lithium perchlorate was added to a solution $1 \mathrm{~N}$ in tetramethyl ammonium hydroxide and $1 \times 10^{-4} \mathrm{~N}$ in dipivaloylmethane. Solution of the following equations yielded the values for the calculation of the formation constant.

$$
\log \frac{\text { Io }}{\mathrm{I}}=\epsilon[\mathrm{DPM}]+\epsilon^{\prime}[[\mathrm{DPM}]+[\mathrm{LiDPM}]]
$$

and

$$
1 \times 10^{-4}=[\mathrm{DPM}]+\left[\mathrm{DPM}^{-}\right]+[\mathrm{LiDPM}] .
$$

The rosults are summarized in Table XLIII. The concentrations given are the equilibrium concentrations. 
Table XI-Determination of pKa Diisobutyrylmethane

$$
\begin{aligned}
& \text { Initial }\left[\mathrm{OH}^{-}\right] \times 10^{4} \quad \mathrm{pKa} \\
& 1.108 \quad 10.13 \\
& 1.662 \quad 10.09 \\
& 2.216 \quad 10.05
\end{aligned}
$$

Table XII-Formation Curve for Acetylacetone Copper(II) Chelate*

$\begin{array}{cccc}\text { ml. KOH } \dagger & -\operatorname{lng}\left[\mathrm{H}^{+}\right] & \mathrm{pA} & \overline{\mathrm{n}} \\ 1.691 & 3.49 & 11.62 & 0.65 \\ 1.792 & 3.55 & 11.56 & 0.68 \\ 1.902 & 3.61 & 11.53 & 0.75 \\ 1.993 & 3.70 & 11.44 & 0.75 \\ 2.093 & 3.80 & 11.35 & 0.78 \\ 2.196 & 3.91 & 11.26 & 0.84 \\ 2.294 & 4.05 & 11.14 & 0.90 \\ 2.404 & 4.24 & 11.00 & 1.00 \\ 2.495 & 4.47 & 10.80 & 1.08 \\ 2.595 & 4.82 & 10.51 & 1.20 \\ 2.695 & 5.20 & 10.23 & 1.36 \\ 2.795 & 6.69 & 9.88 & 1.54 \\ 2.895 & 6.30 & 9.54 & 1.75\end{array}$

* Molar ratin acetylacetone $/ \mathrm{Cu}(\mathrm{II})=\mathbf{2 . 0 0 0}$.

† Concentration 0.0495 molar.

Table XIII-Formation Curve for Acetylacetone Copper(ח) Chelate*

\begin{tabular}{crrr} 
ml. KOH $\dagger$ & $-\log \left[\mathrm{H}^{\top}\right]$ & \multicolumn{1}{c}{$\mathrm{pA}$} & $\overline{\mathrm{n}}$ \\
2.400 & 4.02 & 10.74 & .73 \\
2.503 & 4.21 & 10.62 & 1.22 \\
2.598 & 4.40 & 10.43 & 1.26 \\
3.700 & 4.00 & 10.18 & 1.38 \\
2.800 & 4.97 & 9.91 & 1.53 \\
2.912 & 5.39 & 9.53 & 1.72 \\
3.001 & 5.94 & 9.01 & 1.88 \\
3.030 & 6.36 & 8.60 & 1.93 \\
3.080 & 7.80 & 6.99 & 2.03
\end{tabular}

* Molar ratio acetylacetone $/ \mathrm{Cu}(\mathrm{II})=4.000$.

† Concentration 0.0495 molar. 
Table XIV - Formation Curve for Acetylacetone Copper(II) Chelate*

$\begin{array}{cccc}\text { ml. } \mathrm{KOH} \dagger & -\log \left[\mathrm{H}^{+}\right] & \mathrm{pA} & \overrightarrow{\mathbf{n}} \\ & & & \\ 2.291 & 3.82 & 10.69 & 1.12 \\ 2.392 & 3.92 & 10.57 & 1.14 \\ 2.488 & 4.06 & 10.48 & 1.21 \\ 2.592 & 4.23 & 10.35 & 1.28 \\ 2.689 & 4.40 & 10.18 & 1.36 \\ 2.791 & 4.63 & 10.02 & 1.49 \\ 2.897 & 4.99 & 9.80 & 1.62 \\ 2.991 & 5.62 & 9.59 & 1.77 \\ 3.025 & 6.16 & 8.83 & 1.93 \\ & & 8.27 & 2.01\end{array}$

* Molar ratio acetylacetone $/ \mathrm{Cu}(\mathrm{II})=\mathbf{8 . 0 0}$.

† Concentration 0.0495 molar.

Table XV-Furmation Curve for Acetylacetone Nickel (II) Chelate*

\begin{tabular}{|c|c|c|c|}
\hline ml. $\mathrm{KOH} \dagger$ & $-\log \left[\mathbf{H}^{+}\right]$ & pA & $\overline{\mathbf{n}}$ \\
\hline 2.200 & 5.22 & 9.41 & 0.05 \\
\hline 2.298 & 5.62 & 9.04 & 0.24 \\
\hline 2.399 & 5.97 & 8.71 & 0.43 \\
\hline 2.505 & 6.33 & 8.37 & 0.58 \\
\hline 2.600 & 6.64 & 8.09 & 0.81 \\
\hline 2.702 & 7.07. & 7.68 & 1.00 \\
\hline 2.800 & 7.42 & 7.36 & 1.18 \\
\hline 2.905 & 7.81 & 7.00 & 1.37 \\
\hline 3.000 & 8.18 & 6.66 & 1.55 \\
\hline 3.099 & 8.60 & 6.27 & 1.72 \\
\hline 3.200 & y.3' & 5.54 & 1.92 \\
\hline
\end{tabular}

* Molar ratio acetylacetone $/ \mathrm{Ni}(\mathrm{II})=4.100$.

† Concentration .0461 molar. 
Table XVI - Formation Curve for Acetylacetone Magnesium (II) Chelate*

$\begin{array}{cccc}\mathrm{mL} \text { KOH } \boldsymbol{~} & -\log \left[\mathrm{H}^{\mathbf{+}}\right] & \mathbf{p A} & \overline{\mathbf{n}} \\ 0.000 & & & \\ 0.100 & 5.64 & 8.39 & 0.00 \\ 0.200 & 6.56 & 7.47 & 0.11 \\ 0.300 & 6.94 & 7.10 & 0.21 \\ 0.400 & 7.20 & 6.84 & 0.31 \\ 0.499 & 7.40 & 6.65 & 0.41 \\ 0.600 & 7.57 & 6.48 & 0.51 \\ 0.700 & 7.74 & 6.32 & 0.62 \\ 0.800 & 7.91 & 6.15 & 0.72 \\ 0.900 & 8.07 & 6.00 & 0.82 \\ 1.000 & 8.25 & 5.82 & 0.92 \\ 1.101 & 8.44 & 5.64 & 1.02 \\ 1.300 & 8.62 & 5.46 & 1.13 \\ 1.300 & 0.79 & 5.30 & 1.22 \\ 1.400 & 8.95 & 5.14 & 1.35 \\ 1.500 & 9.08 & 5.02 & 1.42 \\ 1.600 & 9.23 & 4.87 & 1.51 \\ 1.700 & 9.37 & 4.74 & 1.60 \\ 1.800 & 9.50 & 4.62 & 1.69 \\ 1.899 & 9.62 & 4.50 & 1.78 \\ 1.950 & 9.75 & 4.38 & 1.86 \\ & 9.81 & 4.32 & 1.87\end{array}$

* Molar ratio acetylacetone $/ \mathrm{Mg}(\mathrm{II})=\mathbf{9 . 6 1}$.

† Concentration 0428 N molar.

Table XVII — Formation Curve for Acetylacetone Magnesium (II) Chelate*

$\begin{array}{cccc}\text { ml. KOH† } & - \text { log }\left[\mathbf{H}^{\mathbf{+}}\right] & \text { pA } & \overline{\mathbf{n}} \\ 0.000 & 5.42 & 8.31 & 0.00 \\ 0.100 & 6.32 & 7.41 & 0.11 \\ 0.200 & 6.68 & 7.05 & 0.21 \\ 0.300 & 6.92 & 6.81 & 0.31 \\ 0.400 & 7.12 & 6.62 & 0.41 \\ 0.500 & 7.29 & 6.45 & 0.51 \\ 0.600 & 7.46 & 6.28 & 0.62 \\ 0.701 & 7.62 & 6.12 & 0.72 \\ 0.801 & 7.78 & 5.97 & 0.82 \\ 0.900 & 7.96 & 5.79 & 0.92 \\ 1.000 & 8.12 & 5.62 & 1.02 \\ 1.100 & 8.31 & 5.44 & 1.12 \\ 1.200 & 8.48 & 5.28 & 1.22 \\ 1.299 & 8.63 & 5.13 & 1.34 \\ 1.400 & 8.77 & 4.99 & 1.42 \\ 1.500 & 8.92 & 4.84 & 1.51 \\ 1.599 & 9.04 & 4.73 & 1.60 \\ 1.700 & 9.17 & 4.60 & 1.69 \\ 1.800 & 7.30 & 4.47 & 1.77 \\ 1.900 & 9.40 & 4.37 & 1.85 \\ 2.000 & 9.53 & 4.25 & 1.92 \\ & & & \end{array}$

* Molar ratio acetylacetone/ $\mathrm{Mg}(\mathrm{I})=\mathbf{1 9 . 2 2}$.

† Concentration .0428 molar. 
Table XVIII - Formation Curve for Acetylacetone Cobalt(II) Chelate*

$\begin{array}{cccc}\text { ml. KOH } \dagger & -\log \left[\mathrm{H}^{+}\right] & \mathbf{p A} & \overline{\mathbf{n}} \\ & & & \\ 0.000 & 4.77 & 9.56 & 0.00 \\ 0.097 & 5.17 & 9.17 & 0.09 \\ 0.197 & 5.47 & 8.88 & 0.18 \\ 0.297 & 5.70 & 8.66 & 0.26 \\ 0.396 & 5.88 & 8.49 & 0.35 \\ 0.497 & 6.07 & 8.31 & 0.44 \\ 0.598 & 6.22 & 8.17 & 0.53 \\ 0.698 & 6.37 & 8.03 & 0.62 \\ 0.798 & 6.51 & 7.90 & 0.71 \\ 0.899 & 6.67 & 7.75 & 0.80 \\ 0.999 & 6.82 & 7.61 & 0.89 \\ 1.097 & 7.00 & 7.44 & 0.98 \\ 1.198 & 7.18 & 7.28 & 1.07 \\ 1.298 & 7.35 & 7.12 & 1.16 \\ 1.398 & 7.51 & 6.97 & 1.25 \\ 1.499 & 7.68 & 6.82 & 1.34 \\ 1.598 & 7.83 & 6.68 & 1.42 \\ 1.699 & 7.98 & 6.55 & 1.51 \\ 1.798 & 8.17 & 6.37 & 1.60 \\ 1.903 & 8.38 & 6.18 & 1.70 \\ 1.999 & 8.61 & 5.96 & 1.78 \\ 2.098 & 8.91 & 5.68 & 1.87 \\ 2.199 & 9.40 & 5.12 & 1.95\end{array}$

* Molar ratio acetylacetone $/ \mathrm{Co}(\mathrm{II})=4.171$.

† Concentration .0428 molar. 
Table XIX - Formation Curve for Acetylacetone Manganese(II) Chelate*

$\begin{array}{cccc}\text { ml. } \mathrm{KOH} \dagger & -\log \left[\mathrm{H}^{+}\right] & \mathrm{pA} & \overline{\mathbf{n}} \\ & & & \\ 0.000 & 5.16 & 8.87 & 0.00 \\ 0.099 & 5.85 & 8.18 & 0.09 \\ 0.199 & 6.20 & 7.84 & 0.18 \\ 0.298 & 6.44 & 7.60 & 0.27 \\ 0.399 & 6.62 & 7.43 & 0.36 \\ 0.499 & 6.78 & 7.27 & 0.45 \\ 0.599 & 6.93 & 7.13 & 0.53 \\ 0.600 & 7.07 & 0.99 & 0.02 \\ 0.799 & 7.21 & 6.86 & 0.71 \\ 0.901 & 7.35 & 6.72 & 0.80 \\ 1.000 & 7.49 & 6.59 & 0.89 \\ 1.099 & 7.63 & 6.45 & 0.98 \\ 1.200 & 7.79 & 6.30 & 1.07 \\ 1.299 & 7.94 & 6.15 & 1.17 \\ 1.398 & 8.09 & 6.01 & 1.24 \\ 1.499 & 8.25 & 5.85 & 1.33 \\ 1.599 & 8.38 & 5.73 & 1.42 \\ 1.699 & 8.52 & 5.60 & 1.50 \\ 1.800 & 8.66 & 5.46 & 1.59 \\ 1.899 & 8.79 & 5.34 & 1.68 \\ 1.999 & 8.95 & 5.18 & 1.76 \\ 2.099 & 8.09 & 5.05 & 1.05 \\ 2.199 & 9.26 & 4.89 & 1.93\end{array}$

* Molar ratio acetylacetone $/ \mathbf{M n}(\mathrm{II})=8.30$.

† Concentration .0428 molar. 
Table XX — Formation Curve for Acetylacetone Manganese(II) Chelate*

$\begin{array}{cccc}\text { ml. KOH† } & -\log \left[\mathrm{H}^{+}\right] & \text {pA } & \overline{\mathrm{n}} \\ 0.000 & 5.03 & 8.70 & 0.00 \\ 0.100 & 5.64 & 8.09 & 0.09 \\ 0.200 & 5.97 & 7.76 & 0.18 \\ 0.300 & 6.19 & 7.54 & 0.27 \\ 0.400 & 6.37 & 7.37 & 0.36 \\ 0.500 & 6.53 & 7.21 & 0.45 \\ 0.600 & 6.67 & 7.07 & 0.53 \\ 0.703 & 6.79 & 6.95 & 0.63 \\ 0.799 & 6.92 & 6.83 & 0.71 \\ 0.901 & 7.08 & 6.67 & 0.80 \\ 1.000 & 7.24 & 6.51 & 0.89 \\ 1.100 & 7.40 & 6.35 & 0.98 \\ 1.201 & 7.56 & 6.20 & 1.07 \\ 1.300 & 7.71 & 6.05 & 1.17 \\ 1.399 & 7.87 & 5.89 & 1.24 \\ 1.501 & 8.01 . & 5.75 & 1.33 \\ 1.600 & 8.16 & 5.61 & 1.42 \\ 1.700 & 8.29 & 5.48 & 1.50 \\ 1.800 & 8.45 & 5.32 & 1.59 \\ 1.900 & 8.59 & 5.18 & 1.07 \\ 2.000 & 8.75 & 5.03 & 1.75 \\ 2.100 & 8.93 & 4.85 & 1.84 \\ 2.201 & 9.14 & 4.64 & 1.91\end{array}$

* Molar ratio acetylacetone $/ \mathrm{Mn}(\mathrm{II})=16.60$.

$\dagger$ Concentration .0428 molar. 
Table XXI-Formation Curve for Acetylacetone Zinc(II) Chelate*

$\begin{array}{cccc}\text { ml. KOH } \dagger & -\log \left[\mathrm{H}^{+}\right] & \mathrm{pA} & \overline{\mathbf{n}} \\ & & & \\ 0.000 & 4.31 & 9.02 & 0.00 \\ 0.101 & 4.52 & 8.81 & 0.88 \\ 0.200 & 4.73 & 8.60 & 0.17 \\ 0.300 & 4.89 & 8.44 & 0.25 \\ 0.401 & 5.04 & 8.29 & 0.34 \\ 0.500 & 5.19 & 8.14 & 0.42 \\ 0.600 & 5.31 & 8.02 & 0.51 \\ 0.699 & 5.43 & 7.90 & 0.59 \\ 0.790 & 5.54 & 7.79 & 0.60 \\ 0.898 & 5.67 & 7.66 & 0.76 \\ 1.001 & 5.79 & 7.54 & 0.84 \\ 1.100 & 5.91 & 7.42 & 0.93 \\ 1.200 & 6.03 & 7.30 & 1.01 \\ 1.300 & 6.14 & 7.19 & 1.11 \\ 1.400 & 6.26 & 7.08 & 1.18 \\ 1.498 & 6.37 & 6.97 & 1.27 \\ 1.600 & 6.49 & 6.85 & 1.35 \\ 1.701 & 0.00 & 0.74 & 1.43 \\ 1.800 & 6.73 & 6.61 & 1.52 \\ 1.900 & 6.87 & 6.47 & 1.60 \\ 2.000 & 7.03 & 6.31 & 1.69 \\ 2.100 & 7.25 & 6.09 & 1.77 \\ 2.200 & 6.53 & 5.81 & 1.86\end{array}$

* Molar ratio acetylacetone $/ \mathrm{Zn}(\mathrm{II})=39.87$.

† Concentration .0428 molar.

Table XXII - Formation Curve for Dipivaloylmethane Copper(II) Chelate*

$\begin{array}{crrr}\text { ml. KOH† } & -\log \left[\mathrm{H}^{+}\right] & \text {pA } & \overline{\mathbf{n}} \\ & & & \\ 1.394 & 3.29 & 13.79 & .67 \\ 1.601 & .3 .39 & 13.68 & .62 \\ 2.200 & 3.79 & 13.30 & .78 \\ 2.800 & 5.08 & 12.03 & 1.29 \\ 2.980 & 5.38 & 11.75 & 1.46 \\ 3.000 & 5.78 & 11.36 & 1.64\end{array}$

* Molar ratio dipivaloylmethane $/ \mathrm{Cu}(\mathrm{II})=12.00$.

† Concentration 0469 molar. 
Table XXIII-Formation Curve for Dipivaloylmethane Copper(II) Chelate*

$\begin{array}{crrr}\mathrm{ml} . \mathrm{KOH} \dagger & -\log \left[\mathrm{H}^{+}\right] & \mathrm{pA} & \overline{\mathrm{n}} \\ & & & . \\ 1.795 & 3.59 & 13.99 & .40 \\ 1.995 & 3.74 & 13.85 & .48 \\ 2.100 & 3.84 & 13.76 & .52 \\ 2.193 & 3.94 & 13.67 & .58 \\ 2.295 & 4.07 & 13.54 & .65 \\ 2.393 & 4.23 & 13.40 & .73 \\ 2.495 & 4.48 & 13.18 & .82 \\ 2.606 & 4.91 & 12.74 & .93 \\ 2.695 & 5.27 & 12.40 & 1.08 \\ 2.795 & 5.63 & 12.07 & 1.25 \\ 2.895 & 5.98 & 11.75 & 1.44 \\ 2.996 & 6.37 & 11.39 & 1.62 \\ 3.096 & & & 1.80 \\ 3.196 & & & 2.00\end{array}$

* Molar ratio dipivaloylmethane $/ \mathrm{Cu}(\mathrm{II})=4.000$.

† Concentration .0468 molar.

Table XXIV - Formation Curve for Dipivaloylmethane Copper(II) Chelate*

$\begin{array}{cccc}\mathrm{ml} . \mathrm{KOH} \dagger & -\log \left[\mathrm{H}^{+}\right] & \mathrm{pA} & \overline{\mathbf{n}} \\ & & & \\ 1.192 & 3.25 & 14.01 & .48 \\ 1.395 & 3.33 & 13.93 & .49 \\ 1.595 & 3.43 & 13.83 & .48 \\ 1.797 & 3.54 & 13.72 & .527 \\ 1.995 & 3.67 & 13.60 & .600 \\ 2.105 & 3.77 & 13.50 & .630 \\ 2.197 & 3.85 & 13.42 & .68 \\ 2.295 & 3.98 & 13.30 & .72 \\ 2.393 & 4.14 & 13.14 & .78 \\ 2.497 & 4.37 & 12.92 & .85 \\ 2.595 & 4.67 & 12.62 & .964 \\ 2.698 & 5.03 & 12.27 & 1.10 \\ 2.795 & 5.34 & 11.97 & 1.25 \\ 2.897 & 5.68 & 11.64 & 1.44 \\ 2.995 & 6.10 & 11.24 & 1.63 \\ 3.097 & & & 1.81 \\ 3.198 & & & 2.00\end{array}$

* Molar ratio dipivaloylmethane $/ \mathrm{Cu}(\mathrm{II})=8.00$.

† Concentration .0469 molar. 
Table XXV - Formation Curve for Dipivaloylmethane Magnesium (II) Complex*

$\begin{array}{lrrl}\text { ml. } \mathrm{KOH} \dagger & -\log \left[\mathrm{H}^{+}\right] & \text {pA } & \overline{\mathrm{n}} \\ 0.000 & 6.91 & 10.02 & 0.000 \\ 0.104 & 8.54 & 8.39 & 0.1072 \\ 0.200 & 8.96 & 7.98 & 0.206 \\ 0.300 & 9.17 & 7.77 & 0.310 \\ 0.400 & 9.32 & 7.63 & 0.410 \\ 0.500 & 9.46 & 7.49 & 0.515 \\ 0.601 & 9.58 & 7.38 & 0.618 \\ 0.701 & 9.68 & 7.28 & 0.722 \\ 0.800 & 9.77 & 7.20 & 0.825 \\ 0.900 & 9.87 & 7.10 & 0.929 \\ 0.999 & 9.94 & 7.04 & 1.030 \\ 1.100 & 10.03 & 6.95 & 1.132 \\ 1.200 & 10.11 & 6.88 & 1.237 \\ 1.300 & 10.30 & 6.79 & 1.301 \\ 1.400 & 10.29 & 6.71 & 1.442 \\ 1.500 & 10.39 & 6.61 & 1.546 \\ 1.600 & 10.51 & 6.50 & 1.648 \\ 1.700 & 10.66 & 6.35 & 1.750 \\ 1.800 & 10.86 & 6.16 & 1.85 \\ 1.900 & 11.12 & 5.90 & 1.95\end{array}$

* Molar ratio dipivaloylmethane $/ \mathrm{Mg}(\mathrm{II})=9.61$.

† Concentration .0428 molar.

Table XXVI - Formation Curve for Dipivaloylmethane Magnesium(II) Chelate*

$\begin{array}{rrrr}\mathrm{ml} . \mathrm{KOH} \dagger & -\log \left[\mathrm{H}^{+}\right] & \text {pA } & \overline{\mathbf{n}} \\ 0.000 & 7.00 & 9.03 & 0.000 \\ 0.103 & 8.38 & 8.25 & 0.107 \\ 0.200 & 8.70 & 7.93 & 0.21 \\ 0.3 n \mathrm{n} & 8.91 & 7.73 & 0.31 \\ 0.401 & 9.07 & 7.57 & 0.41 \\ 0.500 & 9.17 & 7.47 & 0.52 \\ 0.600 & 9.27 & 7.37 & 0.62 \\ 0.700 & 9.31 & 7.27 & 0.72 \\ 0.800 & 9.47 & 7.18 & 0.83 \\ 0.900 & 9.57 & 7.08 & 0.93 \\ 1.000 & 9.63 & 7.02 & 1.03 \\ 1.101 & 9.74 & 6.91 & 1.13 \\ 1.200 & 9.82 & 6.84 & 1.23 \\ 1.300 & 9.90 & 6.76 & 1.36 \\ 1.401 & 9.99 & 6.67 & 1.44 \\ 1.500 & 10.08 & 6.58 & 1.55 \\ 1.600 & 10.21 & 6.46 & 1.65 \\ 1.700 & 10.36 & 6.31 & 1.75 \\ 1.801 & 10.56 & 6.11 & 1.85 \\ 1.901 & 10.86 & 5.81 & 1.96 \\ 1.925 & 11.02 & 5.65 & 1.99\end{array}$

* Molar ratio dipivaloylmethane $/ \mathrm{Mg}$ (II) $=19.22$.

† Concentration .0428 molar. 
Table XXVII - Formation Curve for Dipivaloylmethane Cobalt(II) Chelate*

\begin{tabular}{|c|c|c|c|c|}
\hline ml. $\mathrm{KOH}$ & & $-\log \left[\mathbf{H}^{+}\right]$ & $\mathrm{pA}$ & $\overline{\mathbf{n}}$ \\
\hline 0.000 & & 5.56 & 11.37 & 0.00 \\
\hline 0.102 & & 6.50 & 10.43 & 0.10 \\
\hline 0.201 & & 6.82 & 10.12 & 0.19 \\
\hline 0.300 & & 7.04 & 9.90 & 0.29 \\
\hline 0.400 & & 7.17 & 9.78 & 0.38 \\
\hline 0.500 & & 7.28 & 9.67 & 0.48 \\
\hline 0.600 & & 7.41 & 9.55 & 0.58 \\
\hline 0.700 & & 7.50 & 9.46 & 0.67 \\
\hline 0.801 & & 7.59 & 9.38 & 0.77 \\
\hline 0.899 & & 7.67 & 9.30 & 0.88 \\
\hline 1.001 & & 7.74 & 9.27 & 0.96 \\
\hline 1.100 & & 7.82 & 9.16 & 1.00 \\
\hline 1.200 & 3 & 7.90 & 9.09 & 1.16 \\
\hline 1.300 & & 7.98 & 9.01 & 1.27 \\
\hline 1.400 & & 8.06 & 8.94 & 1.35 \\
\hline 1.500 & $\vdots$ & 8.15 & 8.85 & 1.44 \\
\hline 1.600 & & 8.23 & 8.78 & 1.54 \\
\hline 1.700 & $\cdot$ & 8.31 & 8.71 & 1.64 \\
\hline 1.800 & & 8.43 & 8.59 & 1.73 \\
\hline 1.901 & & 8.55 & 8.48 & 1.83 \\
\hline 2.000 & & 8.88 & 8.15 & 1.92 \\
\hline
\end{tabular}


Table XXVIII - Formation Curve for Dipivaloylmethane Cobalt(II) Chelate*

\begin{tabular}{|c|c|c|c|}
\hline ml. KOH $†$ & $-\log \left[\mathbf{H}^{+}\right]$ & $\mathbf{p A}$ & $\overline{\mathbf{n}}$ \\
\hline 0.000 & 5.56 & 11.37 & 0.00 \\
\hline 0.102 & 6.50 & 10.43 & 0.10 \\
\hline 0.201 & 6.82 & 10.12 & 0.19 \\
\hline 0.300 & 7.04 & 9.90 & 0.29 \\
\hline 0.400 & 7.17 & 9.78 & 0.38 \\
\hline 0.500 & 7.28 & 9.67 & 0.48 \\
\hline 0.600 & 7.41 & 9.55 & 0.58 \\
\hline 0.700 & 7.60 & 0.46 & 0.07 \\
\hline 0.801 & 7.59 & 9.38 & 0.77 \\
\hline 0.899 & 7.67 & 9.30 & 0.87 \\
\hline 1.001 & 7.74 & 9.24 & 0.96 \\
\hline 1.100 & 7.82 & 9.16 & 1.06 \\
\hline 1.200 & $7: 90$ & 9.09 & 1.16 \\
\hline 1.300 & 7.98 & 9.01 & 1.27 \\
\hline 1.400 & 8.06 & 8.94 & 1.35 \\
\hline 1.500 & 8.15 & 8.85 & 1.44 \\
\hline 1.600 & 0.23 & 8.78 & 1.54 \\
\hline 1.700 & 8.31 & 8.71 & 1.67 \\
\hline 1.800 & 8.43 & 8.59 & 1.73 \\
\hline 1.901 & 8.55 & 8.48 & 1.83 \\
\hline 2.000 & 8.88 & 8.15 & 1.92 \\
\hline
\end{tabular}


Table XXIX-Formation Curve for Dipivaloylmethane Cobalt(II) Chelate*

\begin{tabular}{|c|c|c|c|}
\hline ml. KOH $†$ & $-\log \left[\mathrm{H}^{+}\right]$ & $\mathrm{pA}$ & $\overline{\mathrm{n}}$ \\
\hline 0.000 & 5.39 & 11.24 & 0.00 \\
\hline 0.104 & 6.21 & 10.42 & 0.09 \\
\hline 0.198 & 6.53 & 10.10 & 0.18 \\
\hline 0.299 & 6.69 & 9.94 & 0.27 \\
\hline 0.400 & 6.83 & 9.81 & 0.36 \\
\hline 0.500 & 6.93 & 9.71 & 0.45 \\
\hline 0.600 & 7.03 & 9.61 & 0.54 \\
\hline 0.700 & 7.14 & 9.50 & 0.63 \\
\hline 0.799 & 7.21 & 9.44 & 0.71 \\
\hline 0.900 & 7.28 & 9.37 & 0.80 \\
\hline 0.999 & 7.34 & 9.31 & 0.89 \\
\hline 1.100 & 7.42 & 9.23 & 0.98 \\
\hline 1.200 & 7.49 & 9.17 & 1.07 \\
\hline 1.301 & 7.57 & 9.09 & 1.18 \\
\hline 1.400 & 7.64 & 9.02 & 1.25 \\
\hline 1.501 & 7.70 & 8.96 & 1.34 \\
\hline 1.600 & 7.80 & 8.87 & 1.43 \\
\hline 1.700 & 7.88 & 8.79 & 1.52 \\
\hline 1.800 & 7.95 & 8.72 & 1.61 \\
\hline 1.900 & 8.03 & 8.64 & 1.70 \\
\hline 1.999 & 8.15 & 8.53 & 1.78, \\
\hline 2.100 & 8.42 & 8.26 & 1.88 \\
\hline 2.200 & 9.76 & 6.92 & 1.96 \\
\hline
\end{tabular}


Table XXX - Formation Curve for Dipivaloylmethane Nickel(II) Chelate*

\begin{tabular}{ccrc}
$\mathrm{ml} . \mathrm{KOH} \dagger$ & $-\log \left[\mathrm{H}^{+}\right]$ & $\mathrm{pA}$ & $\overline{\mathrm{n}}$ \\
2.191 & 6.69 & 10.84 & 0.04 \\
2.289 & 7.30 & 10.25 & 0.22 \\
2.391 & 7.58 & 10.00 & 0.41 \\
2.492 & 7.80 & 9.80 & 0.61 \\
2.588 & 7.94 & 9.68 & 0.79 \\
2.691 & 8.06 & 9.59 & 0.98 \\
2.791 & 8.19 & 9.49 & 1.17 \\
2.891 & 8.34 & 9.35 & 1.36 \\
2.991 & 8.52 & 9.22 & 1.55 \\
3.090 & 8.78 & 8.99 & 1.74 \\
3.190 & 9.21 & 8.60 & 1.92 \\
& \multicolumn{4}{c}{} \\
* Molar ratio dipivaloylmethane $/ \mathrm{Ni}(\mathrm{II})=4.100$. \\
† Concentration .0461 molar.
\end{tabular}

Table XXXI-Formation Curve. for Dipivaloylmethane Nickel(II) Chelate*

$\begin{array}{ccrc}\text { ml. KOH } \dagger & -\log \left[\mathrm{H}^{+}\right] & \mathrm{pA} & \overline{\mathbf{n}} \\ 2.195 & & & \\ 2.293 & 6.35 & 10.58 & 0.04 \\ 2.392 & 6.77 & 10.16 & 0.23 \\ 2.495 & 6.97 & 9.97 & 0.41 \\ 2.591 & 7.14 & 9.80 & 0.61 \\ 2.696 & 7.26 & 9.69 & 0.79 \\ 2.793 & 7.40 & 9.55 & 0.99 \\ 2.095 & 7.53 & 9.43 & 1.18 \\ 2.993 & 7.67 & 9.30 & 1.36 \\ 3.094 & 7.94 & 9.03 & 1.55 \\ 3.197 & 8.13 & 8.85 & 1.74 \\ & 8.74 & 8.24 & 1.93 \\ \text { \# Mular ratio dipivaloylmetliane/ NI(I) }=16.40 . \\ \text { † Concentration } .0461 \text { molar. }\end{array}$


Table XXXII - Formation Curve for Dipivaloylmethane Nickel(II) Chelate*

$\begin{array}{crrr}\text { ml. KOH } \dagger & -\log \left[\mathrm{H}^{+}\right] & \mathrm{pA} & \overline{\mathbf{n}} \\ 2.200 & & & \\ 2.300 & 6.05 & 10.48 & 0.05 \\ 2.398 & 6.41 & 10.12 & 0.24 \\ 2.452 & 6.60 & 9.93 & 0.43 \\ 2.512 & 6.68 & 9.85 & 0.52 \\ 2.551 & 6.76 & 9.78 & 0.64 \\ 2.601 & 6.81 & 9.73 & 0.71 \\ 2.650 & 6.86 & 9.68 & 0.81 \\ 2.704 & 6.93 & 9.61 & 0.90 \\ 2.750 & 7.01 & 9.53 & 1.00 \\ 2.798 & 7.07 & 9.47 & 1.09 \\ 2.850 & 7.13 & 9.41 & 1.18 \\ 2.898 & 7.22 & 9.32 & 1.28 \\ 2.953 & 7.31 & 9.24 & 1.37 \\ 2.998 & 7.40 & 9.15 & 1.48 \\ 3.051 & 7.49 & 9.06 & 1.56 \\ 3.102 & 7.61 & 8.94 & 1.66 \\ 3.152 & 7.79 & 8.76 & 1.75 \\ 3.196 & 8.06 & 8.49 & 1.84 \\ 3.249 & 8.48 & 8.07 & 1.93 \\ & 11.00 & 5.00 & 2.01\end{array}$

* Molar ratio dipivaloylmethane $/ \mathrm{Ni}(\mathrm{II})=41.00$. † Concentration 0461 molar. 
Table XXXIII-Formation Curve for Dipivaloylmethane Manganese(II) Chelate*

\begin{tabular}{|c|c|c|c|}
\hline ml. KOH† & $-\log \left[\mathbf{H}^{+}\right]$ & $\mathbf{p A}$ & $\overline{\mathbf{n}}$ \\
\hline 0.000 & 6.43 & 10.20 & 0.00 \\
\hline 0.100 & 7.13 & 9.50 & 0.09 \\
\hline 0.201 & 7.58 & 9.05 & 0.18 \\
\hline 0.300 & 7.84 & 8.79 & 0.27 \\
\hline 0.400 & 8.02 & 8.62 & 0.36 \\
\hline 0.500 & 8.16 & 8.48 & 0.45 \\
\hline 0.601 & 8.29 & 8.35 & 0.53 \\
\hline 0.700 & 8.38 & 8.36 & 0.63 \\
\hline 0.800 & 0.47 & 8.18 & 0.71 \\
\hline 0.801 & 8.55 & 8.10 & 0.80 \\
\hline 1.000 & 8.63 & 8.02 & 0.89 \\
\hline 1.100 & 8.71 & 7.94 & 0.98 \\
\hline 1.200 & 8.79 & 7.87 & 1.07 \\
\hline 1.300 & 8.86 & 7.80 & 1.17 \\
\hline 1.408 & 8.94 & 7.72 & 1.24 \\
\hline 1.500 & 9.03 & 7.63 & 1.33 \\
\hline 1.600 & 9.11 & 7.50 & 1.42 \\
\hline 1.700 & 9.20 & 7.47 & 1.51 \\
\hline 1.800 & 9.32 & 7.38 & 1.60 \\
\hline 1.900 & 9.46 & 7.21 & 1.69 \\
\hline 2.006 & 9.64 & 7.04 & 1.78 \\
\hline 2.100 & 9.9n & 6.78 & 1.87 \\
\hline 2.200 & 10.50 & 6.18 & 1.96 \\
\hline
\end{tabular}


Table XXXIV - Formation Curve for Dipivaloylmethane Manganese(II) Chelate*

$\begin{array}{crrr}\text { ml. KOH } \dagger & -\log \left[\mathrm{H}^{+}\right] & \mathrm{pA} & \overline{\mathbf{n}} \\ 0.000 & & & \\ 0.100 & 6.16 & 10.77 & 0.00 \\ 0.200 & 7.33 & 9.60 & 0.09 \\ 0.300 & 7.86 & 9.08 & 1.18 \\ 0.401 & 8.18 & 8.76 & 0.27 \\ 0.500 & 8.36 & 8.59 & 0.36 \\ 0.600 & 8.50 & 8.45 & 0.45 \\ 0.700 & 8.61 & 8.35 & 0.53 \\ 0.800 & 8.71 & 8.25 & 0.63 \\ 0.900 & 8.80 & 8.17 & 0.71 \\ 1.000 & 8.88 & 8.09 & 0.80 \\ 1.100 & 8.95 & 8.03 & 0.89 \\ 1.200 & 9.03 & 7.95 & 0.98 \\ 1.300 & 9.10 & 7.89 & 1.07 \\ 1.400 & 9.18 & 7.81 & 1.17 \\ 1.500 & 9.26 & 7.74 & 1.24 \\ 1.600 & 9.34 & 7.66 & 1.33 \\ 1.700 & 9.42 & 7.59 & 1.42 \\ 1.800 & 9.51 & 7.51 & 1.51 \\ 1.901 & 9.63 & 7.39 & 1.60 \\ 2.000 & 9.76 & 7.27 & 1.69 \\ 2.100 & 9.90 & 7.13 & 1.78 \\ 2.201 & 10.12 & 6.92 & 1.87 \\ & 10.53 & 6.52 & 1.96 \\ * \text { Molar ratio dipivaloylmethane/Mn(II) } & 8.32 . \\ \dagger \text { Concentration } & .0428 \text { molar. } & & \\ & & & \end{array}$


Table XXXV - Formation Curve for Dipivaloylmethane Zinc(II) Chelate*

$\begin{array}{crrr}\mathrm{ml} . \mathrm{KOH} \dagger & -\log \left[\mathrm{H}^{+}\right] & \mathrm{pA} & \overline{\mathbf{n}} \\ 0.000 & 4.17 & 11.88 & 0.00 \\ 0.101 & \mathbf{5 . 6 2} & 10.41 & 0.88 \\ 0.200 & 5.86 & 10.17 & 0.17 \\ 0.301 & 6.05 & 9.98 & 0.25 \\ 0.400 & 6.18 & 9.85 & 0.34 \\ 0.498 & 6.30 & 9.73 & 0.42 \\ 0.600 & 6.39 & 9.64 & 0.51 \\ 0.700 & 6.49 & 9.54 & 0.59 \\ 0.799 & 6.56 & 9.47 & 0.68 \\ 0.900 & 6.64 & 9.39 & 0.76 \\ 1.000 & 6.70 & 9.33 & 0.84 \\ 1.101 & 6.77 & 9.26 & 0.93 \\ 1.200 & 6.84 & 9.19 & 1.01 \\ 1.300 & 6.92 & 9.11 & 1.11 \\ 1.398 & 6.08 & 9.05 & 1.18 \\ 1.500 & 7.06 & 8.97 & 1.27 \\ 1.600 & 7.14 & 8.89 & 1.35 \\ 1.700 & 7.22 & 8.82 & 1.43 \\ 1.800 & 7.32 & 8.72 & 1.52 \\ 1.800 & 7.41 & 8.63 & 1.60 \\ 2.000 & 7.53 & 8.51 & 1.69 \\ 2.100 & 7.68 & 8.36 & 1.77 \\ 2.200 & 7.93 & 8.11 & 1.86 \\ 2.300 & 8.36 & 7.68 & 1.950\end{array}$

* Molar ratio dipivaloylmethane $/ \mathrm{Zn}(\mathrm{II})=15.76$. p Concentration 0428 molar. 
Table XXXVI-Formation Curve for Dipivaloylmethane Zinc(II) Chelate*

$\begin{array}{cccc}\mathrm{ml} . \mathrm{KOH} \dagger & -\log \left[\mathrm{H}^{+}\right] & \mathrm{pA} & \overline{\mathbf{n}} \\ 0.000 & 5.14 & 11.19 & 0.00 \\ 0.100 & 5.79 & 10.54 & 0.88 \\ 0.200 & 6.17 & 10.16 & 0.17 \\ 0.300 & 6.33 & 10.00 & 0.25 \\ 0.400 & 6.46 & 9.87 & 0.34 \\ 0.500 & 6.59 & 9.74 & 0.42 \\ 0.600 & 6.68 & 9.65 & 0.51 \\ 0.702 & 6.77 & 9.56 & 0.59 \\ 0.800 & 6.85 & 9.48 & 0.68 \\ 0.900 & 6.93 & 9.41 & 0.76 \\ 1.000 & 7.00 & 9.34 & 0.84 \\ 1.101 & 7.09 & 9.25 & 0.93 \\ 1.201 & 7.16 & 9.18 & 1.01 \\ 1.300 & 7.22 & 9.12 & 1.11 \\ 1.401 & 7.29 & 9.05 & 1.18 \\ 1.500 & 7.37 & 8.97 & 1.27 \\ 1.600 & 7.44 & 8.90 & 1.35 \\ 1.700 & 7.53 & 8.82 & 1.43 \\ 1.800 & 7.62 & 8.73 & 1.52 \\ 1.900 & 7.73 & 8.62 & 1.60 \\ 2.002 & 7.86 & 8.49 & 1.69 \\ 2.101 & 7.99 & 8.36 & 1.77 \\ 2.200 & 8.20 & 8.15 & 1.86 \\ 2.309 & 8.56 & 5.78 & 1.95\end{array}$

* Molar ratio dipivaloylmethane $/ \mathrm{Zn}(\mathrm{II})=\mathbf{3 1 . 5 2}$. † Concentration .0428 molar. 
Table XXXVII - Formation Curve for Diisobutyrylmethane Copper(II) Chelate*

$\begin{array}{crrr}\text { ml. KOH } \dagger & - \text { log }\left[\mathbf{H}^{+}\right] & \text {pA } & \overline{\mathbf{n}} \\ 0.000 & 3.45 & 11.61 & 0.724 \\ 0.100 & 3.51 & 11.55 & 0.744 \\ 0.200 & 3.56 & 11.50 & 0.789 \\ 0.309 & 3.62 & 11.45 & 0.826 \\ 0.400 & 3.68 & 11.39 & 0.878 \\ 0.500 & 3.75 & 11.33 & 0.929 \\ 0.600 & 3.86 & 11.22 & 0.962 \\ 0.700 & 3.87 & 11.11 & 1.010 \\ 0.800 & 4.14 & 10.95 & 1.053 \\ 0.901 & 4.32 & 10.77 & 1.116 \\ 1.000 & 4.52 & 10.57 & 1.192 \\ 1.100 & 4.73 & 10.37 & 1.280 \\ 1.200 & 4.93 & 10.18 & 1.385 \\ 1.300 & 5.11 & 10.01 & 1.489 \\ 1.400 & 5.33 & 9.80 & 1.595 \\ 1.500 & 5.56 & 9.59 & 1.705 \\ 1.551 & 5.72 & 9.43 & 1.761 \\ 1.600 & 5.86 & 9.30 & 1.812 \\ 1.650 & 6.05 & 9.11 & 1.868 \\ 1.700 & 6.31 & 8.86 & 1.925 \\ 1.725 & 6.60 & 8.57 & 1.953 \\ 1.750 & 7.13 & 8.04 & 1.982\end{array}$

* Molar ratio diisobuty rylmethane/ $\mathrm{Cu}(\mathrm{I})=4.070$. † Concentration .0556 molar. 
Table XXXVIII - Formation Curve for Diisobutyrylmethane Nickel(II) Chelate*

\begin{tabular}{cccc}
$\mathrm{ml} . \mathrm{KOH} \dagger$ & $-\log \left[\mathrm{H}^{+}\right]$ & $\mathrm{pA}$ & $\overline{\mathbf{n}}$ \\
0.000 & 4.90 & 9.98 & 0.000 \\
0.100 & 5.43 & 9.45 & 0.109 \\
0.200 & 5.84 & 9.05 & 0.228 \\
0.299 & 5.95 & 8.95 & 0.341 \\
0.399 & 6.13 & 8.77 & 0.455 \\
0.500 & 6.26 & 8.65 & 0.569 \\
0.600 & 6.41 & 8.51 & 0.686 \\
0.700 & 6.53 & 8.38 & 0.796 \\
0.800 & 6.65 & 8.28 & 0.909 \\
0.900 & 6.77 & 8.17 & 1.023 \\
0.999 & 6.92 & 8.02 & 1.138 \\
1.099 & 7.07 & 7.88 & 1.250 \\
1.202 & 7.23 & 7.73 & 1.368 \\
1.300 & 7.37 & 7.59 & 1.480 \\
1.400 & 7.57 & 7.40 & 1.592 \\
1.500 & 7.82 & 7.16 & 1.707 \\
1.600 & 8.09 & 6.90 & 1.820 \\
1.700 & 8.77 & 6.23 & 1.932 \\
1.800 & 10.69 & 4.31 & 2.05 \\
& & & \\
$*$ Molar ratio diisobutyrylmethanc/Ni(II) $=8.18$. & & \\
$\dagger$ Concentration & .0556 molar & & \\
\hline & & &
\end{tabular}

Table XXXIX - Formation Curve for Diisobutyrylmethane Magnesium(II) Chelate*

$\begin{array}{crrc}\text { ml. KOH } \dagger & -\log \left[\mathrm{H}^{+}\right] & \mathrm{pA} & \overline{\mathrm{n}} \\ 0.000 & & & \\ 0.101 & 6.27 & 8.61 & 0.000 \\ 0.200 & 7.59 & 7.29 & 0.134 \\ 0.299 & 8.03 & 6.80 & 0.367 \\ 0.398 & 8.30 & 6.60 & 0.400 \\ 0.500 & 8.50 & 6.40 & 0.534 \\ 0.600 & 8.67 & 6.24 & 0.669 \\ 0.698 & 8.81 & 6.11 & 0.800 \\ 0.800 & 8.95 & 5.97 & 0.933 \\ 0.900 & 9.08 & 5.85 & 1.066 \\ 0.999 & 9.22 & 5.72 & 1.198 \\ 1.100 & 9.34 & 5.60 & 1.330 \\ 1.200 & 0.17 & 5.48 & 1.460 \\ 1.300 & 9.61 & 5.35 & 1.593 \\ 1.400 & 9.75 & 5.21 & 1.723 \\ 1.500 & 9.91 & 5.06 & 1.848 \\ 1.600 & 10.07 & 4.91 & 1.972 \\ & 10.24 & 4.75 & 2.091\end{array}$

* Molar ratio diisobutyrylmethane $/ \mathrm{Mg}(\Pi)=10.4 \dot{2}$.

† Concentration .0556 molar. 
Table XL - Formation Curve for Diisobutyrylmethane Cobalt(II) Chelate*

$\begin{array}{cccc}\text { ml. KOH } \dagger & -\log \left[\mathrm{H}^{+}\right] & \text {pA } & \overline{\mathbf{n}} \\ 0.000 & 5.05 & 9.83 & 0.000 \\ 0.101 & 5.74 & 9.14 & 0.107 \\ 0.200 & 6.06 & 8.83 & 0.214 \\ 0.300 & 6.29 & 8.61 & 0.320 \\ 0.400 & 6.46 & 8.44 & 0.427 \\ 0.500 & 6.61 & 8.30 & 0.535 \\ 0.600 & 6.73 & 8.18 & 0.644 \\ 0.701 & 6.04 & 8.08 & 0.748 \\ 0.801 & 6.96 & 7.97 & 0.855 \\ 0.900 & 7.07 & 7.87 & 0.962 \\ 1.003 & 7.19 & 7.75 & 1.069 \\ 1.100 & 7.28 & 7.67 & 1.174 \\ 1.200 & 7.39 & 7.57 & 1.285 \\ 1.302 & 7.53 & 7.43 & 1.390 \\ 1.400 & 7.67 & 7.30 & 1.497 \\ 1.500 & 7.83 & 7.15 & 1.604 \\ 1.600 & 8.00 & 6.99 & 1.710 \\ 1.700 & 8.28 & 6.72 & 1.820 \\ 1.800 & 8.81 & 6.19 & 1.923\end{array}$

* Mular ratio diisöbutyrylmethane $/ \mathrm{Mn}(\mathrm{II})=7.69$.

† Concentration .0556 molar. 
Table XLI - Formation Curve

for Diisobutyrylmethane Manganese(II) Chelate*

\begin{tabular}{lrcc} 
ml. KOH $\dagger$ & $-\log \left[\mathbf{H}^{+}\right]$ & pA & $\overline{\mathbf{n}}$ \\
0.000 & 5.74 & 9.14 & 0.000 \\
0.100 & 6.75 & $\mathbf{8 . 1 3}$ & 0.107 \\
0.202 & 7.14 & 7.75 & 0.214 \\
0.300 & 7.37 & 7.53 & 0.321 \\
0.400 & 7.59 & 7.31 & 0.428 \\
0.501 & 7.73 & 7.18 & 0.536 \\
0.600 & 7.86 & 7.06 & 0.643 \\
0.700 & 8.00 & 6.92 & 0.749 \\
0.801 & 8.13 & 6.80 & 0.856 \\
0.900 & 8.25 & 6.69 & 0.964 \\
1.000 & 8.36 & 6.58 & 1.070 \\
1.100 & 8.50 & 6.45 & 1.175 \\
1.200 & 8.62 & 6.34 & 1.287 \\
1.300 & 8.75 & 6.21 & 1.392 \\
1.400 & 8.89 & 6.08 & 1.498 \\
1.500 & 9.04 & 5.94 & 1.607 \\
1.600 & 9.24 & 5.75 & 1.712 \\
1.700 & 9.47 & 5.53 & 1.820 \\
1.800 & 9.88 & 5.12 & 1.928 \\
& & & \\
* Molar ratio diisobutyrylmethane/Mn(m) = 7.71. & & \\
t Concentration & .0556 molar. & & \\
\hline & & &
\end{tabular}

Table XLII-Formation Constants of beta-Diketones

Acetylacetone

Metal $\quad \begin{array}{llllll}\log K_{1} & \log K_{2} & \log K_{1} / K_{2} & \log K_{1} \quad \log K_{2} \quad \operatorname{lng} K_{1} / K_{8}\end{array}$

$\begin{array}{lrrrrrr}\text { Cu(II) } & 11.57 & 9.64 & 1.90 & 12.29 & 9.99 & 2.30 \\ \mathrm{Ni} \text { (II) } & 8.24 & 6.39 & 1.25 & 8.73 & 7.56 & 1.17 \\ \mathrm{Cd} \text { (I) } & 7.86 & 6.19 & 1.67 & 8.37 & 7.31 & 1.01 \\ \mathrm{Mn}(\text { II) } & 6.81 & 6.18 & 1.63 & 7.23 & 6.07 & 1.16 \\ \mathrm{Mg}(\mathrm{II}) & 6.13 & 4.52 & 1.61 & 6.45 & 5.44 & 1.01\end{array}$

Dipivaloylmethane

$\begin{array}{lrrc}\text { Metal } & \log K_{1} & \log K_{2} & \log K_{1} / K_{2} \\ & & & \\ \text { Cu(II) } & 13.91 & 11.55 & 2.36 \\ \text { Ni(II) } & 9.90 & 9.10 & 0.80 \\ \text { Co(II) } & 9.60 & 8.77 & 0.83 \\ \text { Mn(II) } & 8.34 & 7.44 & \ldots .90 \\ \text { Mg(II) } & 7.44 & 6.59 & 0.85\end{array}$


Copper chelate of dipivaloylmethane

The ultraviolet absorption spectra of a series of solutions whose concentrations of dipivaloylmethane were held constant and concentration of copper perchlorate varied showed an isobestic point at $288 \mathrm{~m} \mu$. This showed the presence of only two species absorbing in this region. The absorption band peaking at $300 \mathrm{~m} \mu$ was taken as that due to some chelated form of dipivaloylmethane. The method of continuous variations was used to indicate the formula of the chelate. The method revealed a mixture of 1-1 and 2-1 chelate. Therefore, the extinction coefficient of bound chelate was assumed to be the same whether it is in the form of a 1-1 or 2-1 chelate.

From the absurbance at $300 \mathrm{~m} \mu$ the constant for the reaction

$$
\mathrm{DPM}+\mathrm{Cu}^{++} \stackrel{\mathrm{Kc}_{1}}{=} \mathrm{Cu} \mathrm{DPM}^{+}+\mathrm{H}^{+}
$$

and

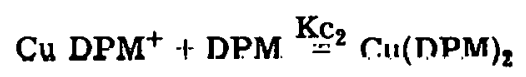

could be calculated. This was possible since the absorbance at $300 \mathrm{~m} \mu$ could be used to calculate [DPM] and [bound DPM], assuming that in a neutral solution [DPM ${ }^{-}$] was negligible, and using the equations

$$
\begin{aligned}
& {[D P M]+[\text { bound DPM }]=1 \times 10^{-4}} \\
& \log \frac{\mathrm{I}_{0}}{I}=\epsilon[\mathrm{DPM}]+\epsilon_{1}[\text { bound DPM }] .
\end{aligned}
$$

$\epsilon_{1}$ was taken from a solution saturated with $\mathrm{Cu}\left(\mathrm{NO}_{3}\right)_{2}$ and containing $1 \times 10^{-4} \mathrm{~N}$ dipivaloylmethane. Knowing the total bound chelate the points could be placed on a Bjerum formation curve, or $\overline{\mathbf{n}}$ was determined from

$$
\overline{\mathbf{n}}=\frac{[\text { bound ligand }]}{[\text { total metal }]}
$$

From two points on the formation curve an estimation of $K_{1}$ was made where $n$ equals 0.5 , and $\mathrm{K}_{2}$ was calculated from the values on the formation curve where $\bar{n}$ equals 1.50 . Using this value for $K_{2}$ a new value of $K_{1}$ was calculated from the values given where $\bar{n}$ equals 0.5 . This process was repeated until agreement was obtained. The formation function used in each case was

$$
\overline{\mathbf{n}}=\frac{\mathrm{K}_{1}[\mathrm{DPM}]\left[\mathrm{H}^{+}\right]+2 \mathrm{~K}_{1} \mathrm{~K}_{2}[\mathrm{DPM}]^{2}}{\left[\mathrm{H}^{+}\right]^{2}+\mathrm{K}_{1}[\mathrm{DPM}]\left[\mathrm{H}^{+}\right]+\mathrm{K}_{1} \mathrm{~K}_{2}[\mathrm{DPM}]^{2}}
$$

where [DPM] is the molar concentration of the unionized species. The [ $\left.\mathrm{H}^{+}\right]$was taken to be equal to the bound ligand concentration. The two values $K_{1}$ and $K_{2}$ are:

$$
\operatorname{lng} K_{1}=13.40 \quad \log K_{2}=12.78
$$

where

$$
K_{n}=\frac{K_{n}}{K_{i} K_{W}} \quad K_{i}=\frac{[D P M]}{[D P M]\left[\mathrm{OH}^{-}\right]}
$$

and $\mathrm{K}_{\mathrm{w}}=2.8 \times 10^{-16}(36)$.

Since potentiometric titrations of copper metal ion in 50 percent dioxane (38) showed that considerable hydrolysis of the metal takes place at low $\mathrm{pH}$ readings, the formation constants determined by this method do not agree at all with the potentiometric method. It is probable 
also that some hydrolysis of the monochelated metal occurs and that the absorption characteristics are similar to those of $\mathrm{MA}$ and $\mathrm{MA}_{2}$.

In this case suitable concentration ranges were not used so that formation and hydrolysis constants could not be obtained by the use of the two methods simultaneously. A method employing both techniques would be useful in this regard since the potentiometric method enables the measurement of $\left[\mathrm{H}^{+}\right]$liberated.

$$
\left[\mathrm{H}^{+}\right] \text {liberated }=\mathrm{MA}+2 \mathrm{MA}_{2}+2 \mathrm{MA}(\mathrm{OH})+\mathrm{MOH}+2 \mathrm{M}(\mathrm{OH})_{2}
$$

Spectrophotometric measurement would give [bound chelate].

$$
[\text { bound chelate }]=\mathrm{MA}+2 \mathrm{MA}_{2}+\mathrm{MAOH}
$$

then if we ignore $\mathrm{MOH}$ and $\mathrm{M}(\mathrm{OH})_{2}$

$$
\left[\mathrm{H}^{+}\right] \text {liberated }-[\text { bound chelate }]=\mathrm{MAOH}
$$

An estimation of the amount of metal in the form of $\mathrm{MOH}$ and $\mathrm{M}(\mathrm{OH})_{2}$ may be made from the potentiometric titration curve of the metal ion alone. Difficulty was encountered in attempts to make this measurement when precipitation occurred early in the titration when 75 percent dioxane was used.

Table XLII - Determination of Formation Constant of the Lithium Chelate of Dipivaloylmethane in 50 Percent Water-Dioxane

Concentrations of substituents

$\begin{array}{cccc}\mathrm{OH}^{-} \times 10^{4} & \mathrm{Li}^{+} \times 10^{4} & \mathrm{DPM}^{-} \times 10^{4} & \log \mathrm{K}_{1} \\ 0.0106 & 2.19 & 0.477 & 3.47 \\ 0.0106 & 2.19 & 0.477 & 3.47 \\ 0.0106 & 4.51 & 0.355 & 3.48\end{array}$

\section{DISCUSSION}

Infrared and Ultraviolet Spectra

The close similarity of the infrared spectra of dipivaloylmethane and its lithium chelate clearly indicate the similarity of their structures. It is, however, difficult to account for a weak and diffuse band occurring in the chelating agent at about 2600 wave numbers unless this is assigned to the $\mathrm{OH}$ stretching frequency. This assignment was made when this band did not appear in the copper chelate and shifted to longer wavelengths for the deuterated chelating agent. This assignment was also made by Rasmussen (39). The spectra obtained at high resolution using lithium fluoride optics did not reveal any simple relationship to the fact that the enol form of beta-diketones contains an aromatic hydrogen.

The enolic content of beta-diketones can be revealed by their infrared spectra. K. Kuratani (35) has developed an analytical method for enol content based upon the absorption of the carbonyl and conjugated carbonyl groups at 1710 and $1600 \mathrm{~cm} .^{-1}$ respectively. Kuratani found that p-methoxybenzoyl-pivaloylmethane was 100 percent enolized in non polar solvents by this method. Spectra of diisobutyrylmethane and dipivaloylmethane reveal no unconjugated carbonyl (diketone form) in the pure liquid. Further evidence can be obtained from the ultraviolet spectra where the extinction coefficient remains high for dipivaloylmethane in acetonitrile and decreases in the series toward acetylacetone. Water appears to exert a leveling effect upon the keto-enol equilibrium since all are 15 to 18 percent enolized in this solvent. 
It has been shown that the introduction of alkyl groups on the methylene groups of acetylacetone and acetoacetic esters decreases the tendency to enolize (40). This is explained by the steric hindrance between the methyl groups of the cyclic enol form. The infrared absorption spectra of 3-methylacetylacetone reveal a strong $\mathrm{OH}$ stretching frequency undoubtedly due to the enol being largely present in the acyclic form. Considerable absorption is also noted at $1710 \mathrm{~cm} .^{-1}$ indicating a large amount of the diketone form.

Examination of molecular models reveals how increasing the steric requirements on the terminal methyl groups of acetylacetone may increase the enol content. It is possible to construct models corresponding to structure I and II for acetylacetone.

Dipivaloylmethane and diisobutyrylmethanc may be constructed only in the furm II in which the steric hindrance between the $R$ groups is minimum and the repulsion between the carbonyl dipoles is maximum. Such a structure as $I$ is stabilized when a proton is removed from the methylene carbon and placed between the two carbonyl dipoles to form the enol III. Thus, the stability of the diketone form is reduced as the steric requirements of the $R$ groups increase.

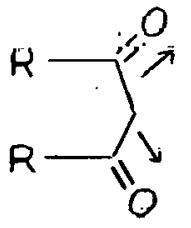

I

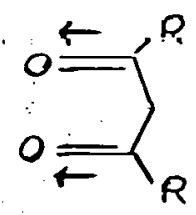

II<smiles>[R]C(=O)C=C([R])OC</smiles>

IIII

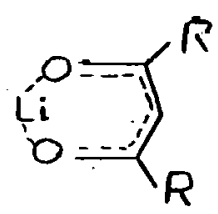

IV

Evidence to indicate that Structure $\mathrm{II}$ is that of the enol form is the largely displaced carbonyl stretching frequency appearing at $1600 \mathrm{~cm} .^{-1}$ which differs greatly from the normal carbonyl stretching frequency (above $1700 \mathrm{~cm} .{ }^{-1}$ ). The similarity of the absorption spectra of the chelating agent and that of the lithium chelate, especially in the $1600 \mathrm{~cm} .^{-1}$ region, also supports Structure III. The chelate is shown in Structure IV.

\section{Variation of Acidity with Steric Requirements}

The same factors which were uscd above to describe the instability of the diketone form where $R$ is large may be used to describe the instability of the anions of the same compounds. Here the dipolar repulsion of the carbonyl groups is augmented in the absence of the shielding proton and with a full negative charge concentrated on the carbonyls.

A striking correlation is found between the rates of alkaline hydrolysis of ethyl esters in 85 percent ethanol of the compounds<smiles>[R]C(=O)OCC</smiles>

and the pKa of the beta-diketones where the $\mathbf{R}$ group of the ester is the same as the terminal $\mathbf{R}$ groups of the beta-diketones. The same correlation exists for the rate constants of ketonization (ur enulization). 'I'he excellent limear relatlunship is shown in F'igure 8 . 'The agreement is so good that fortuity does not give a satisfactory explanation. Hammett has demonstrated that such linearity commonly exists only for meta and para substituted benzoic acid derivatives (41). In the case of the ester hydrolysis of aliphatic esters, $\Delta \Delta \mathbf{s}^{ \pm}$does not remain constant as the series where $R$ equals methyl, $i$-propyl, and $t$-butyl progresses. That $\Delta \Delta s^{ \pm}$remains zero or nearly so for a serles of meta or para substituted benzoic acid derivatives, is demonstrated by Hammett and helps constitute a simple explanation for the correlation of structure and reactivity. It is not understood why linearity should appear in this case. Enolization requires an attack by a base on the methyleine carbon, whereas ester hydrolysis requires attack by the basic reagent on the carbonyl carbon; yet there is a direct relationship between the steric influences on the two reactions. Linear relationships such as those demonstrated here are not unusual in organic chemistry. However, no rigorous treatment has been given to them. 


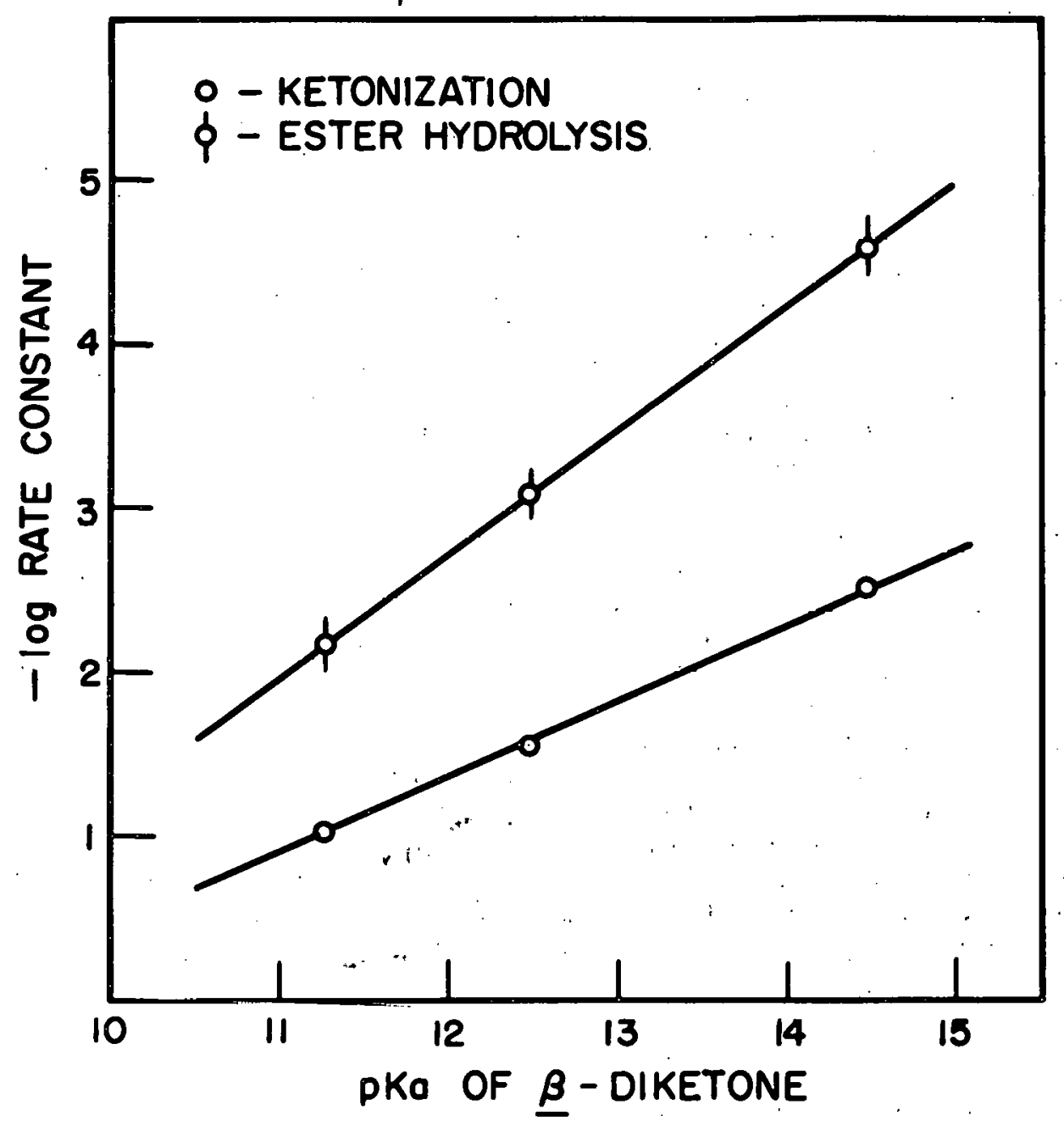

Fig. 8-Correlation between kinetic and equilibrium data for beta-diketones. 
Formation Constants of Metal Chelates of beta-Diketones

According to the argument presented in the historical section, a plot of the first formation constant for a series of metal chelates of acetylacetone against the corresponding constants for the chelates of dipivaloylmethane of disobutyrylmethane should not give a straight line. As the data of Irving (33) demonstrates, metal chelates of metals with high Edwards' beta values such as $\mathrm{Cu}$ (II) should deviate considerably from linearity; the deviation being in the direction of the more stable chelate. Plots of this type are given in Figures 9 and 10.

That $\log \mathrm{K}_{1}$ for $\mathrm{Cu}(\mathrm{II})$ does not fall to the right of the line drawn indicates this constant is low for dipivaloylmethane and diisobutyrylmethane. A similar plot of $\log \mathrm{K}_{2}$ shows that the second constant is much lower than would be expected for the two diketones since the point falls far to the left of the line.

This evidence does not in itself constitute proof that both $\log K_{1}$ and $\log K_{2}$ are relatively low for $\mathrm{Cu}$ (II) since the beta values for the other metals are not given by Edwards. However, of the metals listed, $\mathrm{Cu}$ (II) has the highest beta, which is about 1.5 times greater than the value for $\mathrm{Zn}(\mathrm{II})$.

The plot of log formation constant against pKa of the chelating agent as shown in Figure 11 reveals the low vilue for $\log \mathrm{K}_{1} \mathrm{~K}_{2}$ for copper chelates if diisobutyrylmethane aud ulplvaloylmethanè, but does not indicate $\log K_{1}$ for these chelates to be too low.

The copper chelate of acetylacetone has been shown to have a square planar configuration (42) and that of the nickel chelate is known to be tetrahedral (43). It is not likely that any of the other metals used in this study would form square complexes. If square complexes are formed from bulky ligands it is more probably that the effect of the bulk will be reflected in the formation constants than if a tetrahedral complex is formed. This appears to be the case with $\mathrm{Cu}(\mathrm{II})$ where the maximum steric effect is observed. Although a molecular model of the copper chelate of dipivaloylmethane does not show any steric hindrance between the two adjacent ligands, $\log \mathrm{K}_{1} \mathrm{~K}_{2}$ appears to be low for this compound. Molecular models, however, cannot show to what extent the ligand interferes with the solvation of the chelated metal. It is probably that both interference with solvation and between ligands contribute to the low formation constants.

Further evidence is shown by the relatively large separation factor for the copper chelates of the hindered reagents. If this is attributed to steric effects, it is paradoxical to state that the abnormally small separation factor for the hindered chelates of the remaining metals is due to the same effect. However, when we consider that a tetrahedral configuration can tolerate greater steric requirements in the ligands, it follows that the steric inhibition to solvation would becume more important in determining the difference between the first and second formation constants. It thus appears that a monochelated metal is more acidic toward the second ligand when complexing with bulkier reagents, due to the more effective removal of water of solvation. This effect is merely masked for copper by. another steric effect.

Extrartinn nf Lithium Ion by Dipivaluyluethane

The selectivity of dipivaloylmethane toward lithium may he attributed to two factors. The first is the small size of the lithium ion (0.60A) (44) as compared with the sodium (0.95 $\AA$ ) and

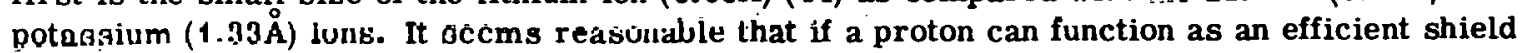
between the oxygens, any small positive ion may likewise form a shield (Structure IV). The inability to measure a formation constant for the sodium chelate in the same manner that the stability of the lithium chelate was measured clearly indicates the specificity for lithium. Differences in the structures between the lithium chelate and the sodium chelates are indicated in the infrared spectra (45).

The second factor, which is closely related to the first, is the desolvating powers of dipivaloylmethane. That ether was the only efficient solvent found indicates that the monochelated lithium ion still may solvate quite well, but the added organic bulk merely facilitates the displacement of water by ether. The factors influencing the solubilities of the alkati metal chelates of this reagent, and the changes which occur in absorption spectra with solvation are now. under investigation (45). 


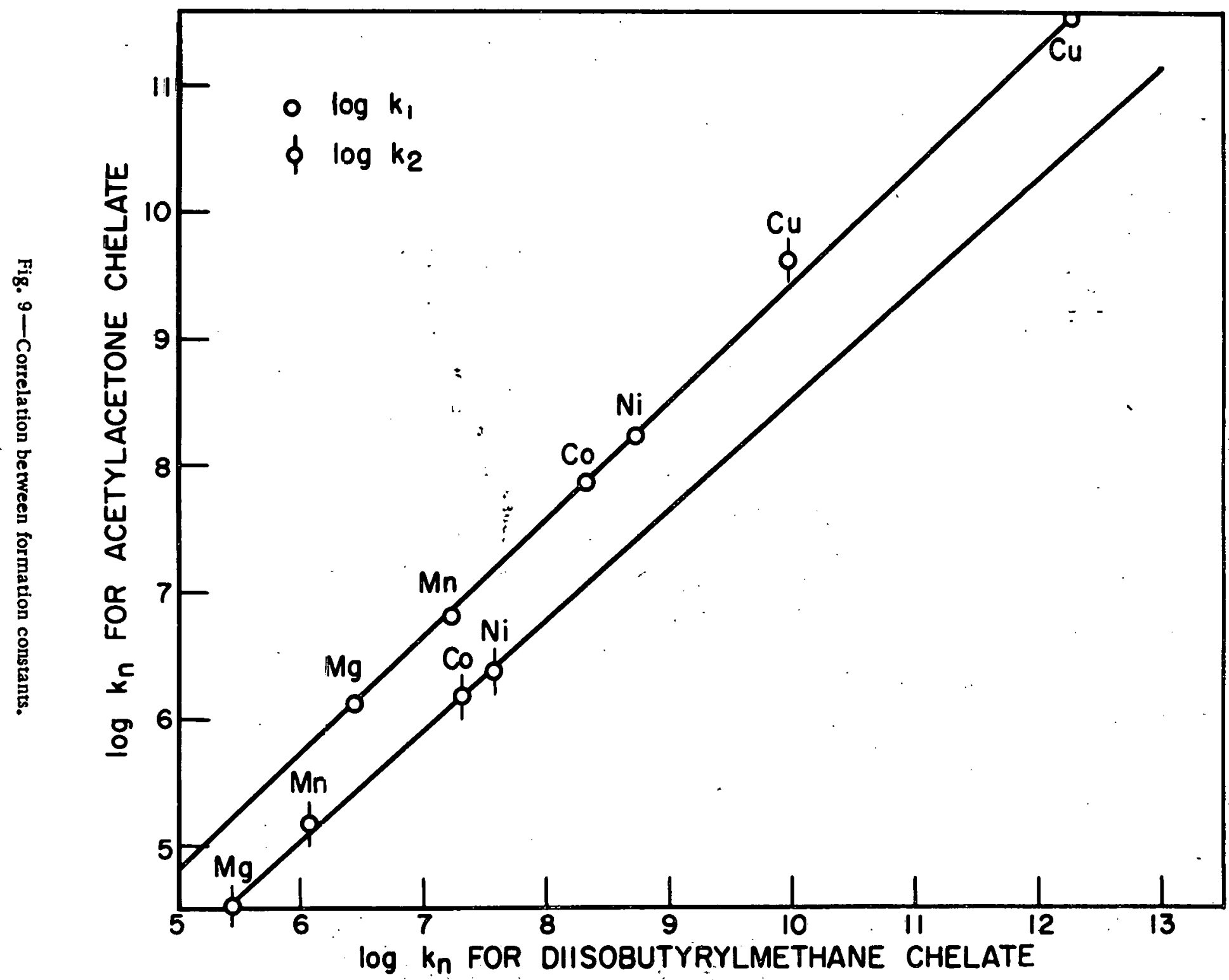




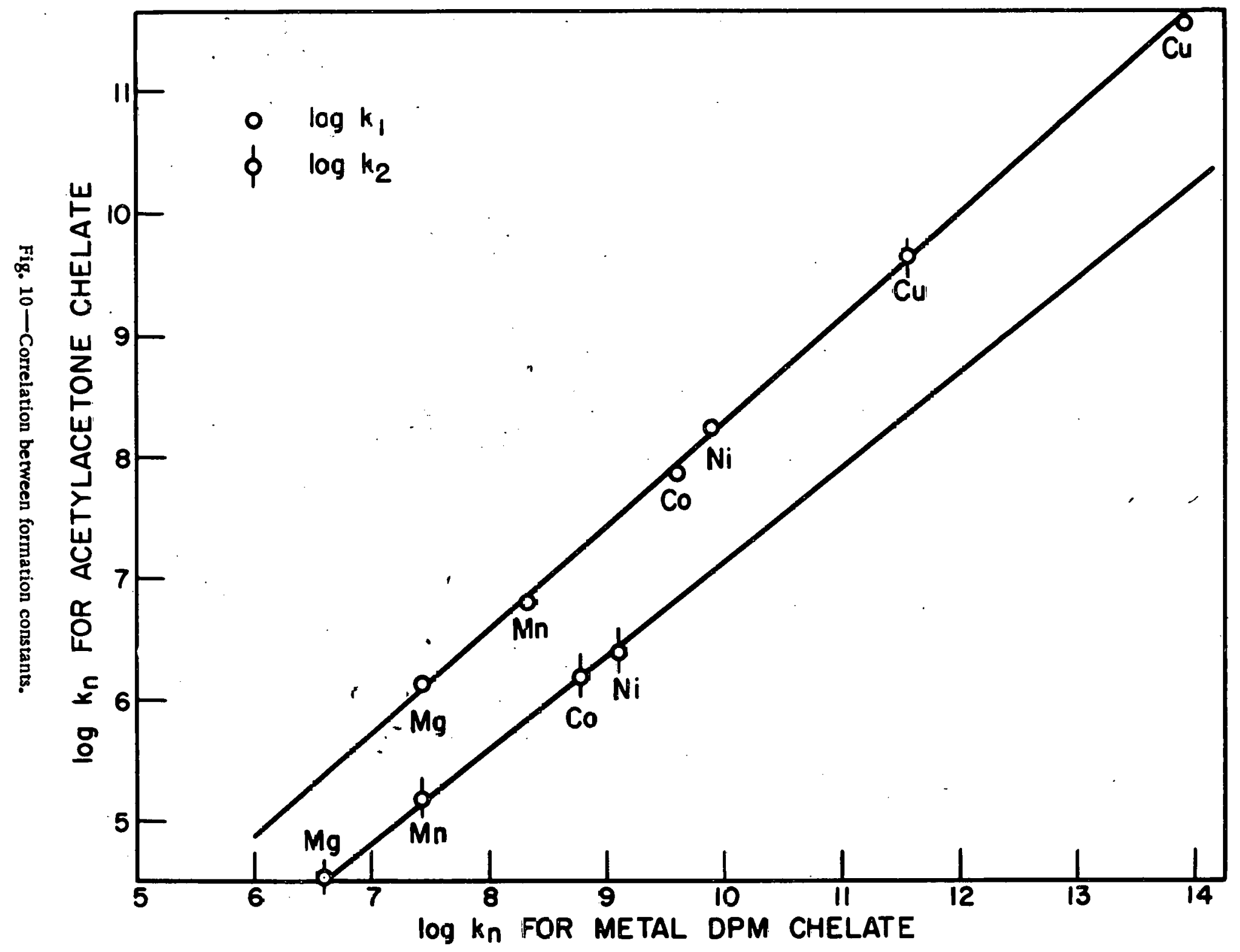




$$
4
$$

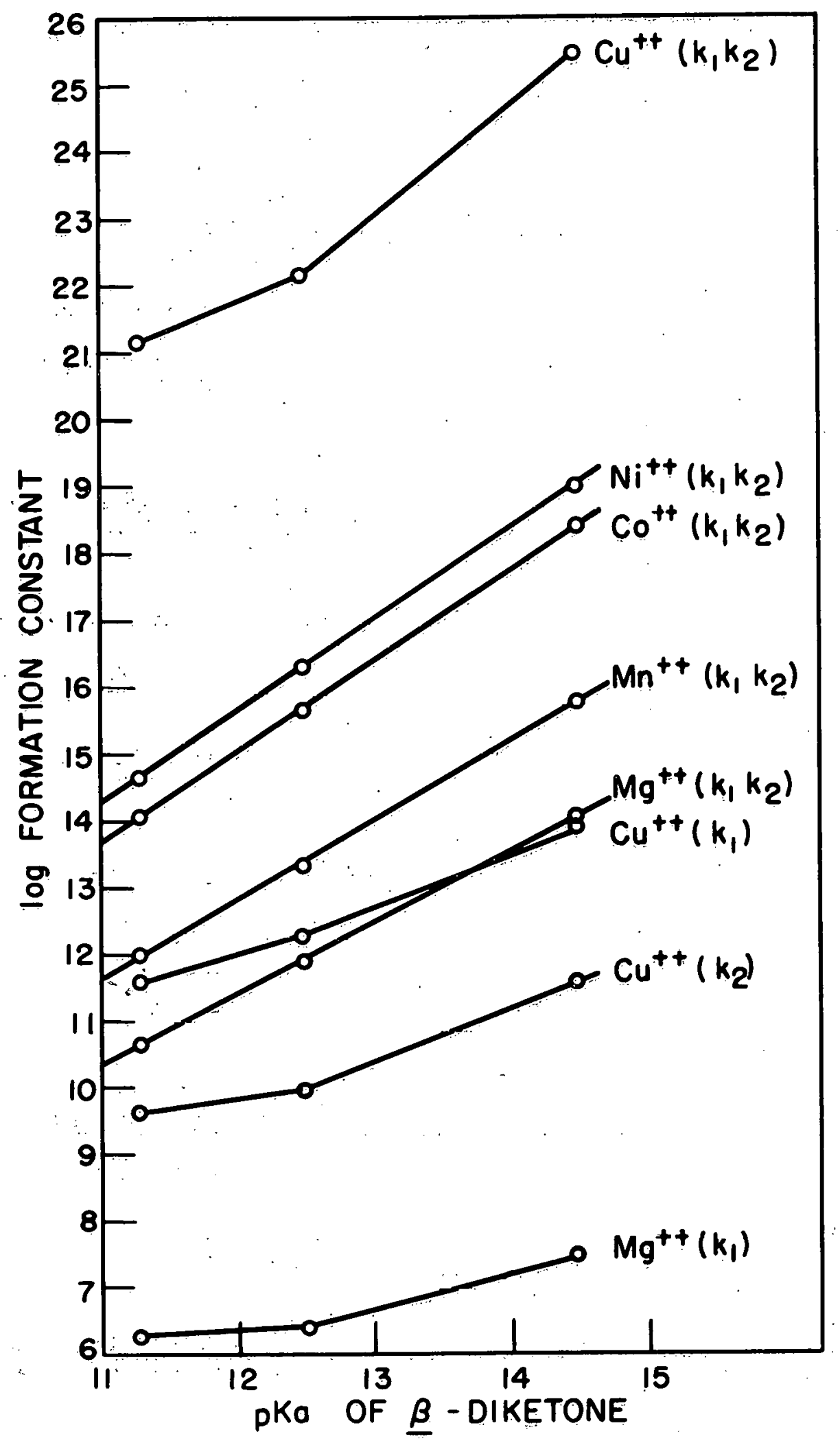

Fig. 11-Correlation of formation constants with basicity. 


\section{BIBLIOGRAPHY}

1. J. Bjerrum, "Metal Ammine Formation in Aqueous Solution", P. Hasse and Sons, Copenhagen (1941).

2. G. T. Morgan and R. W. Thomasson, J. Chem. Soc., 125745 (1924).

3. M. Leser, Bull. Soc. Chim. France, $21, \overline{546(1899)}$.

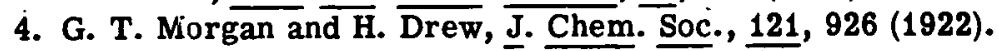

5. and ibid., 125,760 (1924).

6. M. Calvin and K. Wilson, J. Am. Chem. Soc., 67, 2003 (1945).

7. H. Irving, E. J. Butler, and M. F. Ring, J. Chem. Soc., 1489 (1949).

8. H. Freiser and W. D. Johnston, J. Am. Chem. Soc., 74, 5239 (1952).

9. , Rec. Chem. Prog., $\overline{14,199} \overline{(1953) \text {. }}$

10. A. E. Martell and M. Calvin, "Chemistry of the Metal Chelate Compounds", Prentice-Hall, N. Y., 1952, p. 278.

11. D. P. Mellur and W. H. Lockwood, J. Proc. Rev. Soc. N. S. Wales, 74, 141 (1940).

12. R. Bruehlman and F. Verhoek, J. Am. Chem. Soc. $70, \overline{1401} \overline{(1948)}$.

13. J. Djerrum, Chem. Reviews, 46, 381 (1950).

14. H. Irving and J. M. Griffiths, J. Chem. Soc., 213 (1954).

15. A. F. Trotman-Dickenson, J. Chem. Soc., 1293 (1949).

16. H. C. Brown, H. Bartholomay, and M. D. Taylor, J. Am. Chem. Soc., 66, 435 (1944).

17. A. E. Martell and M. Calvin, "Chemistry of the Metal Chelate Compounds", Prentice-Hall, N. Y. 1952, Ch. 4.

18. and , ibid., p. 134.

19. H. Irving, R. J. Williams, D. J. Ferrett, and A. E. Williams, J. Chem. Soc., 3494 (1954).

20. G. Schwarzenback, Helv. Chim. Acta., 36, 23 (1953).

21. A. E. Martell and M. Calvin, "Chemistry of the Metal Chelate Compounds", Prentice-Hall, N. Y., 1952, p. 171-180.

22. H. Irving and A. Hampton, J. Chem. Soc., 430 (1955).

23. G. W. Wheland, "The Theory of Resonance", John Wlley and Sons, N. Y., 1947, p. 209.

24. L. Van Uitert; B. E. Douglas, and W. C. Fernelius, A. E. C. Report N. Y. O. - 727, May 2, 1951.

25. J. O. Edwards, J. Am. Chem. Sni., 76, 1540 (1054).

26. L. P. Hammett, "Physical Organic Chemistry", McGraw-Hill, N. Y., $194 n$.

27. R. M. Milburn, J. Am. Chem. Soc., 77, 2064 (1955).

28. H. Irving, R. Williams, D. Fer'ett, and A. Williams, J. Chem. Soc., 2494 (1954).

29. W. W. Brandt and J. P. Wright, J. Am. Chem. Soc., $7 \overline{6} ; \overline{3082}(1 \overline{954})$.

30. L. Van Uitert, W. C. Fernelius, and B. E. Douglas, ibid., 75, 457 (1953).

31. J. T. Adams and C. R. Hauser, J. Am. Chem. Sac., $\overline{66}, 12 \overline{20}-2$ (1944).

32. and , ibid., $6 \overline{6}, 347$ (1944).

33. H. Irving and H. S. Rossotti, J. Chem. Soc., 2910 (1934).

34. G. Schwarzenbach and E. Felder, Helv. Chim. Acta, 27, 1044 (1944).

35. K. K. Kuratani, Reports of the Institute of Science and Technology of the University of Tokyo, 6 (1952).

36. H. S. Harned and B. B. Owen, "The Physical Chemistry of Electrolytic Solutions", Reinhold, N. Y., 1950, p. 581 .

37. G. S. Hammond and W. Bordiun, Ames, Iowa, unpublished research.

38. R. G. Charles and H. Freiser, J. Am. Chem. Soc., 74, 1385 (1952).

39. R. S. Rasmussen, D. D. Turncliff, and R. R. Brattain, lbid., 71, 1068 (1949).

40. J. B. Conant and A. F. Thompson, ibid., 54, 4039 (1932).

41. L. P. Hammett, "Physical Organic Chemistry", McGraw-Hill, N. Y., 1940, p. 185.

42. L. Pauling, "The Nature of the Chemical Bond", Cornell University Press, Ithaca, N. Y., 1948, p. 119.

43. E. G. Cox and K. C. Webster, J. Chem. Soc., 731 (1935).

44. L. Pauling, "The Nature of the Chemical Bond", Cornell University Press, Ithaca, N. Y., p. 346.

45. G. S. Hammond and A. W. Fort, Ames, Iowa, unpublished research. 